\title{
Exploring Protein Structures by DNP-Enhanced Methyl Solid-State NMR Spectroscopy
}

\author{
Jiafei Mao ${ }^{1,2 *}$, Victoria Aladin ${ }^{2,3,4}$, Xinsheng $\mathrm{Jin}^{5}$, \\ Alexander J. Leeder ${ }^{6}$, Lynda J. Brown ${ }^{6}$, Richard C.D. Brown ${ }^{6}$, \\ Xiao He $\mathrm{He}^{5,7}$, Björn Corzilius ${ }^{1,2,3,4}$, Clemens Glaubitz ${ }^{1,2 *}$
}

1. Institute of Biophysical Chemistry, Goethe University Frankfurt, 60438 Frankfurt am Main, Germany

2. Institute of Physical and Theoretical Chemistry, Goethe University Frankfurt, 60438 Frankfurt am Main, Germany

3. Centre for Biomolecular Magnetic Resonance, Goethe University Frankfurt, 60438 Frankfurt am Main, Germany

4. Institute of Chemistry and Department Life, Light \& Matter, University of Rostock, 18055 Rostock, Germany

5. Shanghai Engineering Research Center of Molecular Therapeutics and New Drug Development, School of Chemistry and Molecular Engineering, East China Normal University, Shanghai, 200062, China

6. Department of Chemistry, University of Southampton, Southampton SO17 1BJ, United Kingdom

7. NYU-ECNU Center for Computational Chemistry at NYU Shanghai, Shanghai, 200062, China

(*) j.mao@em.uni-frankfurt.de, glaubitz@em.uni-frankfurt.de Institute of Biophysical Chemistry

Goethe University Frankfurt

Max-von-Laue-Str. 9

60438 Frankfurt am Main

Germany

Tel.: +49-69-798-29927

Fax.: +49-69-798-29929 


\begin{abstract}
Although the rapid development of sensitivity-enhanced solid-state NMR (ssNMR) spectroscopy based on dynamic nuclear polarization (DNP) has enabled a broad range of novel applications in material- and life sciences, further methodological improvements are needed in order to unleash the full potential of DNP-ssNMR. Here, a new methyl-based toolkit for exploring protein structures is presented, which combines signal-enhancement by DNP with heteronuclear Overhauser effect (hetNOE), carbon-carbon-spin diffusion (SD) and strategically designed isotope-labeling schemes. It is demonstrated that within this framework, methyl groups can serve as dynamic sensors for probing local molecular packing within proteins. Furthermore, they can be used as 'NMR torches' to selectively enlighten their molecular environment e.g. to selectively enhance the polarization of nuclei within residues of ligand-binding pockets. Finally, the use of ${ }^{13} \mathrm{C}-{ }^{13} \mathrm{C}$ spin diffusion enables probing carbon-carbon distances within the subnanometer range, which bridges the gap between conventional ${ }^{13} \mathrm{C}$-ssNMR methods and EPR spectroscopy. The applicability of these methods is directly shown on a large membrane protein, the light-driven proton pump green proteorhodopsin (GPR), which offers new insight into the functional mechanism of the early step of its photocycle.
\end{abstract}

\title{
Keywords
}

solid-state NMR, dynamic nuclear polarization, heteronuclear Overhauser effect, methyl group, proteorhodopsin, photocycle, membrane protein, ligand-protein interaction, spin diffusion 


\section{Introduction}

In recent years magic-angle-spinning solid-state nuclear magnetic resonance (MAS ssNMR) spectroscopy has made impressive progress in decoding structure and dynamics of biomolecules. ${ }^{1-9}$ In particular, in combination with dynamic nuclear polarization (DNP) that breaks the sensitivity limit of conventional NMR spectroscopy, ssNMR has become a valuable tool for exploring challenging proteins. ${ }^{10-13}$ It has been shown to be especially powerful for obtaining mechanistic insights into important membrane proteins. ${ }^{14-22}$ The recent progress in structural biology, especially due to time-resolved serial femtosecond crystallography (TR-SFX) ${ }^{23-24}$ and single particle cryo- electron microscopy (cryo-EM) ${ }^{8}$, ${ }^{25-26}$, offers an unparalleled starting point for in-depth mechanistic studies for which spectroscopic tools such as ssNMR will play an important role.

Recently, an NMR phenomenon called heteronuclear Overhauser effect (hNOE), which is well-known to solution-state NMR spectroscopists, ${ }^{27}$ has been reinvestigated in the context of DNP-enhanced ssNMR spectroscopy. ${ }^{28-29}$ It has been shown that the ${ }^{1} \mathrm{H}$ hyperpolarization prepared by DNP can be transferred to ${ }^{13} \mathrm{C}$ nuclei via the stochastic ${ }^{1} \mathrm{H}$ ${ }^{13} \mathrm{C}$ cross-relaxation processes within methyl groups undergoing fast reorientation around the methyl axis (Fig. 1a). This leads to characteristic methyl ${ }^{13} \mathrm{C}$ signals of strong negative intensities distinguishable from those ${ }^{13} \mathrm{C}$ signals yielded from other conventionally used polarization transfer pathways. In fact, methyl NMR spectroscopy has been very successful in both the liquid- and solid-state for studying the structures and dynamics of large and complex proteins. ${ }^{30-38}$ In addition, the hNOE phenomenon has been already investigated in a few organic and biological solids for probing local dynamics. ${ }^{39-42}$ Inspired by these works, we demonstrate here a promising toolkit for structural and mechanistic investigations of biological macromolecules based on the integration of cross-effect (CE) DNP, methyl ${ }^{1} \mathrm{H}-{ }^{13} \mathrm{C}$ hNOE, the well-known phenomenon of ${ }^{13} \mathrm{C}-{ }^{13} \mathrm{C}$ spin diffusion (SD) together with sparse ${ }^{13} \mathrm{C}$ labeling schemes. SD transfers the polarization among like-nuclei e.g. ${ }^{13} \mathrm{C}$ spins in a coherent fashion via a spin-spin flip-flop process. It has served as the foundation of a numerous number of NMR methods and applications on a vast range of materials and biosolids. ${ }^{43-46}$ Here, we show directly for the $30 \mathrm{kDa}$ membrane protein green proteorhodopsin (GPR), ${ }^{47}$ that the hNOE build-up kinetics of methyl groups under DNP conditions can report on local molecular packing. Furthermore, it is possible to 'highlight' selectively ${ }^{13} \mathrm{C}$-labeled sites in proximity of methyl groups, which simplifies complex DNP ssNMR spectra, and to extract subnanometer distances between methyl groups and surrounding ${ }^{13} \mathrm{C}$ sites. 
GPRs form the largest microbial rhodopsin (Type-1 rhodopsin) family distributed widely in marine bacteria. ${ }^{48-49}$ They convert light into an $\mathrm{H}^{+}$electrochemical gradient crossing the cellular membrane, which represents an additional source of energy and eventually enhances the survival of the marine bacterial communities. Light-driven ion pumps could also be engineered as molecular tools with broad applications in the growing field of optogenetics. Typically for a rhodopsin, the retinal chromophore in PRs is covalently bound to Lys231 in helix G via a protonated Schiff base (pSB) moiety (Fig. 1d). Proton pumping is achieved by a complex photocycle involving distinct metastable photointermediates (Fig. S1) ${ }^{50}$ It is initiated by the photoexcitation of its dark state (ground state) retinal chromophore followed by a retinal trans-cis isomerization reaction of the $\mathrm{C} 13=\mathrm{C} 14$ bond leading to the K-state photointermediate (Fig. 1e, f). The K-state is subsequently converted to the early-M state featuring the initial proton transfer from the SB nitrogen to its counter ion(s) (Fig. S1).

Despite the remarkable efforts on the structural and dynamical studies of PR over the last decade $14,17,49,51-58$ and even the successful ssNMR characterization of its photointermediates, ${ }^{51-52}$ many mechanistic details of the photocycle events remain unresolved. The new hNOE-based DNP approach presented here has enabled us to probe the molecular interactions of the retinal C20 methyl group with its protein surrounding in the dark and K-state GPR, which reveal unexpected molecular features.

\section{Results and discussions}

\section{DNP hNOE ssNMR spectroscopy on retinal methyl groups in GPR}

We have first focused on the retinal cofactor in GPR and have introduced ${ }^{13} \mathrm{C}$-labeled methyl groups at positions C16/C17/C18 or C20 (Fig. 2a, b). These labeling schemes have been explored in search for a 'well-behaving' methyl group in hNOE experiments under DNP conditions. The pulse program presented in Fig. $1 \mathrm{~b}$ has been used for obtaining the ${ }^{1} \mathrm{H}-{ }^{13} \mathrm{C}$ hNOE signals by removing the broad ${ }^{13} \mathrm{C}$ background signals attributed to the direct ${ }^{13} \mathrm{C}$ hyperpolarization. ${ }^{28,59}$ In this work, we have performed all ssNMR experiments in conjugation with CE DNP using the AMUPol biradical ${ }^{60}$ as polarization agent. On $\left[{ }^{13} \mathrm{C}_{12,13,20}\right.$-retinal]-GPR, in which the retinal $\mathrm{C} 20$ methyl group is ${ }^{13} \mathrm{C}$-labeled, a pronounced ${ }^{13} \mathrm{C}$ signal of negative intensity, characteristic for the hNOE process under DNP, can already be observed in the methyl region on the 1D spectrum (Fig. 2a) acquired at $110 \mathrm{~K}$ using the pulse program shown in Fig. $1 \mathrm{~b}$ (using $1 \mathrm{~s}$ polarization delay). This ${ }^{13} \mathrm{C}$ signal can be unambiguously assigned to the $\mathrm{C} 20$ methyl group located on the polyene chain as 
compared with the double-quantum-filtered (DQF) ${ }^{13} \mathrm{C} 1 \mathrm{D}$ spectrum of the same sample (Fig. 2a) which selects the nearby paired ${ }^{13} \mathrm{C}$ sites. Similarly, we have also observed an hNOE ${ }^{13} \mathrm{C}$ signal for $\left[{ }^{13} \mathrm{C}_{10-18}\right.$-retinal]-GPR, in which $\mathrm{C} 16, \mathrm{C} 17$ and $\mathrm{C} 18$ methyl groups on the ionone ring are ${ }^{13} \mathrm{C}$-labeled (Fig. $2 \mathrm{~b}$ ). This ${ }^{13} \mathrm{C}$ signal can be assigned to $\mathrm{C} 18$ methyl group as $\mathrm{C} 16$ and $\mathrm{C} 17$ methyl group show rather distinct chemical shifts (Fig. S2). In contrast to $\mathrm{C} 18$, the $\mathrm{C} 16$ and $\mathrm{C} 17$ methyl groups show no observable $\mathrm{hNOE}{ }^{13} \mathrm{C}$ signals under the same experimental condition (Fig. 2b). These two 'hNOE-silent' methyl groups are both located on a quaternary carbon. The crowded local environment could impede their reorientation and compromise the hNOE efficiency by shifting the $\mathrm{CH}_{3}$ reorientation rate to an unfavorable regime. Similarly, a previous study has shown that methyl groups on a $-\mathrm{N}\left(\mathrm{CH}_{3}\right)_{2}$ moiety also exhibit very weak hNOE signals at temperatures close to our condition. ${ }^{61}$ These observations suggest that the hNOE efficiency of methyl groups under these conditions depends on chemical structures and the local environment.

It is interesting to note that the hNOE ${ }^{13} \mathrm{C}$ spectrum of $\left[{ }^{13} \mathrm{C}_{12,13,20}\right.$-retinal]-GPR also shows negative intensities of non-methyl $\mathrm{C} 12$ and $\mathrm{C} 13$ sites (Fig. 2a), while for $\left[{ }^{13} \mathrm{C}_{10-18^{-}}\right.$ retinal]-GPR only the methyl C18 signal is detected (Fig. 2b). These observations already indicate the possibility of a distance-dependent magnetization transfer from a methyl group to neighboring carbons, which will be discussed further below.

\section{hNOE build-up kinetics of methyl groups reports on local molecular packing}

Since the C20 methyl group is located next to the retinal isomerization site, we have focused on this methyl group and have further investigated its hNOE build-up kinetics. As depicted in Fig. 1a, the matrix protons near the DNP biradical AMUPol ${ }^{60}$ are first hyperpolarized via CE DNP under our experimental conditions. ${ }^{62}$ Through the rapid ${ }^{1} \mathrm{H}-{ }^{1} \mathrm{H}$ spin diffusion, the large ${ }^{1} \mathrm{H}$ polarization of these initial DNP sites transfers to the other protons in the sample, including those on the reorienting $\mathrm{CH}_{3}$ group where the $\mathrm{hNOE}$ process takes place (Fig. 1a). The propagation of the ${ }^{1} \mathrm{H}$ polarization from the initial CEDNP hotspots in the DNP matrix to the interested retinal methyl groups in GPR molecules embedded in the lipid bilayer could potentially rate-limit the subsequent hNOE process. We therefore have chosen a fully protonated matrix in order to benefit from fast ${ }^{1} \mathrm{H}-{ }^{1} \mathrm{H} S \mathrm{SD}$. We have also explored various matrix/sample deuteration schemes, which did not lead to any significant advantage on our GPR proteoliposome samples (Fig. S3).

The hNOE build-up time constant ( $\mathrm{T}_{\mathrm{hNOE}}$ ) of the retinal $\mathrm{C} 20$ methyl group in fully protonated GPR sample is $3.0 \mathrm{~s}$ at $110 \mathrm{~K}$ (Fig. 3a, Fig. S4a). In comparison, the DNP- 
build-up time constant of bulk ${ }^{1} \mathrm{H}$ in our samples is about $1 \mathrm{~s}$ (Fig. S5). This is significantly smaller than the measured $\mathrm{T}_{\mathrm{hNOE}}$ and indicates that the recorded $\mathrm{hNOE}$ build-up kinetics is indeed not dictated/limited by the ${ }^{1} \mathrm{H}$ polarization propagation. In order to estimate the methyl dynamics underlining such an efficient hNOE process, we have mapped the potential energy surface (PES) of the C20 methyl group in a GPR structural model based on the blue PR X-ray structure by QM/MM calculations (Fig. 3b). The calculated energy barrier $(10.1 \mathrm{~kJ} / \mathrm{mol})$ points to the time scale of methyl reorientation about methyl axis in the ns regime (or in the order of $10^{2} \mathrm{MHz}$ ) at $110 \mathrm{~K} \cdot{ }^{63-64} \mathrm{This}$ is in the order of ${ }^{1} \mathrm{H}$ and ${ }^{13} \mathrm{C}$ Larmor frequencies at the magnetic field used in our experiments $\left(400 \mathrm{MHz}\right.$ for ${ }^{1} \mathrm{H}, 100$ $\mathrm{MHz}$ for $\left.{ }^{13} \mathrm{C}\right)$ and therefore could activate efficiently the ${ }^{1} \mathrm{H}-{ }^{13} \mathrm{C}$ zero-quantum $\left(\mathrm{ZQ},\left(\omega_{\mathrm{H}}-\right.\right.$ $\left.\left.\omega_{c}\right) / 2 \pi=300 \mathrm{MHz}\right) /$ double-quantum $\left(\mathrm{DQ},\left(\omega_{H}+\omega_{\mathrm{C}}\right) / 2 \pi=500 \mathrm{MHz}\right)$ cross-relaxation processes that drive the hNOE. In solution NMR, the methyl groups have been intensively used as probes for sensing the local structural changes in proteins. In addition, the backbone NH hNOE is a widely used parameter for mapping protein dynamics. The possibility in correlating the methyl hNOE build-up kinetics under DNP conditions with the methyl reorientation rate, as suggested by our QM/MM calculations, has encouraged us to explore further the potential of this ssNMR parameter as a dynamic sensor in proteins.

Previously, several groups have reported DNP ssNMR studies on the photointermediates of microbial rhodopsins prepared by light illumination. ${ }^{15}, 22,51-52,65-66$ Our recent studies on GPR photointermediates focused on the retinal chromophore ${ }^{51}$ as well as on interactions at the protomer interface ${ }^{52}$. So far, the retinal-protein coupling in different photointermediates, which links retinal photochemistry with protein functions, remains under-explored. Upon light absorption by GPR, the all-trans retinal cofactor isomerizes to 13-cis yielding the early K-state photointermediate. Since C20 is located next to this isomerization site (Fig. 1f), it could serve as a strategic NMR probe for studying retinal-protein interactions in different photo states. Upon in-situ illumination of GPR under cryogenic conditions $(110 \mathrm{~K})$, the K-state can be generated and trapped. The retinal C20 carbon experiences a large down-field shift by about $10 \mathrm{ppm}$, indicating that this site is indeed sensitive to the trans-to-cis conversion of the retinal polyene chain (Fig. 2c). In contrast, retinal $\mathrm{C} 18$ on the ionone ring moiety shows no observable chemical shift changes upon the formation of K-intermediate (Fig. 2d). Since only a part of the sample can be converted into the K-state, the spectrum in Fig. 2c shows two well-resolved C20 resonances from the dark as well as K-state, which permits a direct comparison of their methyl hNOE behaviors. 
At $110 \mathrm{~K}$ the hNOE build-up kinetics of $\mathrm{C} 20$ in the K-intermediate is significantly slower than in the dark state (Fig. 3a, Fig. S4a). In order to decode the differences in the hNOE kinetics of these two states, we have monitored the temperature-dependence of C20 hNOE build-up kinetics. Surprisingly, an opposite behavior with increasing temperature is observed featuring growing hNOE build-up time constant in the dark state and decreasing hNOE build-up time constant in the K intermediate (Fig. 3a, Fig. S4b-c). Similar to the ${ }^{13} \mathrm{C}$ longitudinal relaxation ( $\mathrm{T}_{1}$ relaxation), the hNOE build-up rate shows approximately a bimodal dependence on the methyl reorientation rate/correlation time (Fig. 3c). As mentioned above, the hNOE build-up is most efficient when the methyl reorientation rate approaches the regime of ${ }^{1} \mathrm{H}-{ }^{13} \mathrm{C} Z Q / D Q$ transition rates. We have taken the theoretical model of an isolated ${ }^{13} \mathrm{CH}_{3}$ spin system and sketched the relationship between $T_{\text {hNOE }}$ and the correlation time of methyl reorientation $\left(\mathrm{T}_{\mathrm{r}}\right)$. The details of this model can be found in SI. As plotted in Fig. 3c, $T_{h N O E}$ increases when the rate of the methyl motion shifts away from the $D Q / Z Q$ transition rate. It has to be mentioned that under our experimental conditions, the hNOE process is also coupled to other processes as shown in Fig. 1a and its detailed relationship with the methyl reorientation rate is expected to be somewhat different from the simplified model on an isolated methyl group. Nevertheless, the sketch in Fig. $3 \mathrm{c}$ shall still be valid qualitatively for the applications in this work since (i) the preceding processes (DNP, ${ }^{1} \mathrm{H}-{ }^{1} \mathrm{H} S \mathrm{SD}$ ) do not rate-limit the hNOE as mentioned above, (ii) the retinal C20 methyl group is embedded in the central part of PR and shielded away from radicals and (iii) we only focus on the difference in the hNOE build-up kinetics between the ground state and the K-photointermediate. In the K-state photointermediate, $T_{\text {hNOE }}$ of the C20 methyl group decreases gradually upon the acceleration in methyl reorientation by raising the sample temperature from $110 \mathrm{~K}$ to $140 \mathrm{~K}$ (Fig. 3a, Fig. S4c). Guided by Fig. 3c, such a behavior indicates that within this temperature range the C20 methyl reorientation in the K-state of GPR is slower than the optimal methyl reorientation rate driving the fastest hNOE build-up (Fig. 3c blue branch). In contrast, the C20 methyl reorientation in dark state shows an opposite trend (Fig. 3a, Fig. S4b), namely the slower hNOE process at higher temperature, and therefore can be depicted by the "fast reorientation" branch (red) in Fig. 3c. This analysis shows that the C20 methyl reorientation is slower in the K-state compared to the dark state.

This observation seems contradictive to the reduction in intra-retinal hindrance on the $\mathrm{C} 20$ methyl group upon the photoisomerization. In the all-trans configuration, the C15$\mathrm{H} 15$ moiety is close to C20. The steric hindrance caused by this moiety is reduced in 13- 
cis configuration, where just $\mathrm{H} 14$ is located at this position. Therefore, the slowed $\mathrm{C} 20$ methyl reorientation in the K-state of GPR should be due to the additional steric hindrance by the protein-retinal contacts established in this early photointermediate. It has been shown by X-ray crystallography that upon the formation of the late K-state of bacteriorhodopsin (BR), the C20 methyl group moves toward bulky Trp residues Trp185 and Leu93 at the intracellular side. These two residues are also conserved in the GPR clade and the Trp capping the C20 methyl group (Fig. 3d) is even conserved in all outward $\mathrm{H}^{+}$-pumping microbial rhodopsins. The structural model of the dark-state GPR (Fig. 3d) indicates that the retinal photoisomerization could push the C20 methyl group toward the bulky side chain of Trp197 and Leu105. This movement leads to a tighter packing of the retinal cofactor against its protein environment (Fig. 3d), which is compatible with our finding of a slowed C20 methyl reorientation in the K-state based on the hNOE data. Here, the hNOE build-up kinetics, which can be easily measured on methyl groups as dynamic NMR reporters, carries key biophysical information on the ligand-protein coupling.

This demonstration showcases the value of methyl hNOE SSNMR in probing the local structure/packing in different functional states of proteins. This approach could also be complementary to other classical ssNMR methods such as ${ }^{1} \mathrm{H} /{ }^{13} \mathrm{C} /{ }^{2} \mathrm{H} \mathrm{T}_{1}$ measurements that is often less selective due to the spin diffusion or signal overlapping. In particular, the conventional ${ }^{13} \mathrm{C} \mathrm{T}_{1}$ measurement can be affected by ${ }^{1} \mathrm{H}-{ }^{13} \mathrm{C}$ cross-relaxation and in fact hNOE kinetics has to be taken into account in those experiments. ${ }^{67}$

\section{Selective detection of Internuclear contacts by Methyl PoLarization Enhancement (SIMPLE)}

In the previous section, we have utilized a retinal methyl group as a local sensor to probe indirectly its interaction with the protein environment via the hNOE effect. Though such an approach could already offer valuable information, the direct NMR detection of surrounding nuclei is still required for establishing a more complete picture on the retinalprotein coupling within the binding pocket in different photointermediate states. In our case, such NMR detection could be enabled by further transferring the ${ }^{13} \mathrm{C}$ hyperpolarization of the retinal $\mathrm{C} 20$ methyl group to nearby retinal/protein ${ }^{13} \mathrm{C}$ nuclei via ${ }^{13} \mathrm{C}-{ }^{13} \mathrm{C}$ SD (Fig. 1a, d). Since the SD process occurs even without active dipole-dipole or CSA recoupling under the moderate MAS rates $(8 \mathrm{kHz})$ used in this work, the same pulse program shown in Fig. $1 \mathrm{~b}$ can be used for this purpose without modifications. The ${ }^{13} \mathrm{C}-{ }^{13} \mathrm{C}$ $\mathrm{SD}$ rate via dipolar coupling follows an $\mathrm{r}^{-6}$ distance dependence (Eq. S1). Therefore, retinal 
carbons $\mathrm{C} 12$ (1.5 $\AA$ to $\mathrm{C} 20)$ and $\mathrm{C} 13$ (2.6 $\AA$ to $\mathrm{C} 20)$, which are in close proximity to the hyperpolarized hNOE methyl hotspot $\mathrm{C} 20$ in $\left[{ }^{13} \mathrm{C}_{12,13,20}\right.$-retinal]-GPR, should receive ${ }^{13} \mathrm{C}$ polarization via SD more efficiently (on the ms time scale for directly bonded ${ }^{13} \mathrm{C}$-carbons) than more distal sites (Fig. 4a). As already shown above in Fig 2a, the ${ }^{13} \mathrm{C}$ signals of these two sites build up ${ }^{13} \mathrm{C}$ polarization simultaneously to C20 (Fig. S6). This observation indicates that the magnetization transfer from carbon $\mathrm{C} 20$ to nearby carbons $\mathrm{C} 12 / \mathrm{C} 13$ via SD occurs more rapidly than the methyl hNOE build-up or a direct hNOE transfer from methyl ${ }^{1} \mathrm{H}$ to $\mathrm{C} 12 / \mathrm{C} 13$. The latter process should occur at significantly slower rates for two and three-bond distances as shown previously. ${ }^{59} \mathrm{In}$ contrast, no signals in addition to $\mathrm{C} 18$ could be detected in $\left[{ }^{13} \mathrm{C}_{10-18}\right.$-retinal]-GPR at short polarization delay (1 $\left.\mathrm{s}\right)$, since retinal carbons C10-C15 are far away from the C18 hNOE hotspot (Fig. 2b).

Usually, ssNMR spectra of ligands in complex with large proteins free of natural abundance protein ${ }^{13} \mathrm{C}$ background $(1.1 \%)$ are obtained by double-quantum filtering (DQF, Fig. 2a, b) and/or by ${ }^{13} \mathrm{C}$ depletion. Here, the combination of hNOE and SD offers an attractive alternative way for the detection of ligands in complexes. In $\left[{ }^{13} \mathrm{C}_{10-18}\right.$-retinal]GPR, our approach visualizes the $\mathrm{C} 18$ methyl group, which is distant from other ${ }^{13} \mathrm{C}$ sites and therefore cannot be captured by the conventional 1D DQF CP experiment.

Following the successful selective detection of the retinal polyene $\mathrm{C} 12$ and $\mathrm{C} 13$, we have further explored the possibility to detect protein residues near the C20 methyl group using the similar approach. We have first targeted the highly conserved residue Tyr200 located in the retinal binding pocket of GPR (Fig. 4b). A DQF CP ${ }^{13} \mathrm{C}$ NMR spectrum of [U- ${ }^{13} \mathrm{C}$-Tyr]-GPR (Fig. 4c) shows overlapping signal of all Tyr residues in GPR. In order to visualize selectively the Tyr200 residue, we have labeled the unique Tyr200-Pro201 pair in GPR by incorporating ${ }^{15} \mathrm{~N}$-labeled proline and ${ }^{13} \mathrm{C}$-labeled tyrosine during protein expression ([U- ${ }^{13} \mathrm{C}-\mathrm{Tyr}, \mathrm{U}-{ }^{15} \mathrm{~N}-\mathrm{Pro}$-GPR). In such a sample, a unique correlation between the ${ }^{15} \mathrm{~N}$-Pro signal, which is well separated from the backbone amide nitrogen peaks, with the Tyr ${ }^{13} \mathrm{C}$ resonances can be observed in $2 \mathrm{D} \mathrm{N}(\mathrm{CO}) \mathrm{CX}$ spectra (Fig. 4d). All Tyr200 ${ }^{13} \mathrm{C}$ resonances can be resolved. Of course, such an approach is largely limited to cases of unique/rare residue pairs. Since Tyr200 is located near to retinal C20 methyl group (ca. 4 $\AA$ to $C 20$ and ca. $3 \AA$ to $C 12$, Fig. $4 \mathrm{~b}$ ), we have also explored the possibility of visualizing this residue via hNOE-SD in a sample labeled at both ${ }^{13} \mathrm{C}$-Tyr and ${ }^{13} \mathrm{C}_{12,13,20}$-retinal sites

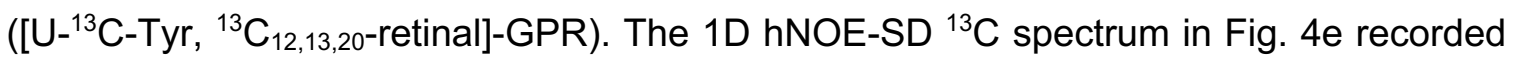
with a short polarization delay of $1.0 \mathrm{~s}$ shows a set of ${ }^{13} \mathrm{C}$ signals identical to those identified for Tyr200 in Fig. 4d. These resonances are in the same phase as retinal 
carbons (phase already adjusted by $180^{\circ}$ in Fig. 4e), suggesting that the source of their magnetization is the $\mathrm{C} 20$ hyperpolarization created by DNP and hNOE. Indeed, without retinal labeling ([U- $\left.\left.{ }^{13} \mathrm{C}-\mathrm{Ty} r\right]-\mathrm{GPR}\right)$, these unique protein signals are not observed using the same approach (Fig. S7a). The $\mathrm{Tyr}{ }^{13} \mathrm{C}$ signals in the hNOE-SD spectrum at a short buildup time do not match the positions in the $1 \mathrm{D} D Q F C P{ }^{13} \mathrm{C}$ spectrum representing the sum of all Tyr signals (Fig. 4c, e). Upon increasing the build-up time, additional Tyr signals appear and the spectra closer resemble the DQF ${ }^{13} \mathrm{C}$ spectrum (Fig. S8a). These observations suggest that ${ }^{13} \mathrm{C}$ hyperpolarization on the retinal ligand is transported to other more distal $\mathrm{U}-{ }^{13} \mathrm{C}$-Tyr sites at lower rates. In comparison, the direct ${ }^{1} \mathrm{H}-\mathrm{Tyr}{ }^{13} \mathrm{C}$ hNOE transfer only yields a minor contribution to the observed Tyr signals in $\left[\mathrm{U}-{ }^{13} \mathrm{C}-\mathrm{Tyr}\right.$,

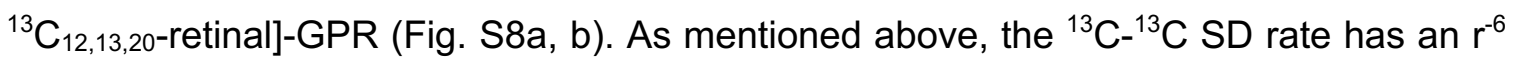
distance dependence. Therefore, the Tyr200 residue next to C20 methyl group (4.2 $\AA$ to $\mathrm{C} 20,3.2 \AA$ to $\mathrm{C} 12$ ) should be the primary hyperpolarization recipient and its ${ }^{13} \mathrm{C}$ signal can be selectively observed on $1 \mathrm{D}$ hNOE-SD ${ }^{13} \mathrm{C}$ spectrum with a short build-up time $(1 \mathrm{~s}$ in this case, Fig. 4d-e). These data demonstrate a new NMR approach for the Selective Detection of Internuclear Contacts by Methyl PoLarization Enhancement (SIMPLE) that utilizes the methyl hNOE hotspot as the 'NMR torch' to enlighten selectively the nearby residues. In particular, the possibility of creating local hyperpolarization on a strategically placed methyl group, which could be delivered via ligand binding, offers a range of attractive options for applications to challenging ligand-protein complexes.

In a previous work on an uniformly ${ }^{13} \mathrm{C}$-labeled RNA-ligand complex using ligand hNOE (SCREAM-DNP, Specific Cross-Relaxation Enhancement by Active Motions under $D N P),{ }^{61}$ the selectivity of ligand-RNA ${ }^{13} \mathrm{C}-{ }^{13} \mathrm{C}$ SD transfer is hampered by the slow initial hNOE build-up of hindered methyl groups in competition with fast distribution of polarization within the dense ${ }^{13} \mathrm{C}$ network in the uniformly labeled biopolymer. It has been however demonstrated that an hNOE effect could be used to observe selectively the NMR signal of the RNA-ligand complex by 'activating' methyl groups suffering from steric hindrance at higher temperatures. ${ }^{61}$

In the SIMPLE approach, the ${ }^{13} \mathrm{C}-{ }^{13} \mathrm{C}$ SD is effectively slowed down in the highly diluted ${ }^{13} \mathrm{C}$ network created by the tailored ${ }^{13} \mathrm{C}$ isotope labeling schemes. This together with the fast hNOE kinetics of less-hindered methyl groups permits the ${ }^{13} \mathrm{C}$ hyperpolarization of the methyl hNOE hotspot to be transferred primarily to nearby protein/ligand ${ }^{13} \mathrm{C}$ sites over those distal sites. This approach relies on the rational design of ${ }^{13} \mathrm{C}$ labeling schemes, which result in suitable hNOE and SD build-up kinetics. SIMPLE 
exhibits very high site selectivity by combining not only the biochemical specificity of the ligand-protein recognition, but also the hNOE selectivity on "well-behaving" methyl groups, the slowed ${ }^{13} \mathrm{C}-{ }^{13} \mathrm{C}$ SD kinetics by the sparse ${ }^{13} \mathrm{C}$ labeling, and the ${ }^{13} \mathrm{C}$ spin-pair selectivity of ${ }^{13} \mathrm{C}-{ }^{13} \mathrm{C} \mathrm{SD}$ (ZQ process). Such a high selectivity would strongly support its applications in the scenarios previously explored by targeted-DNP approaches based on chemically modified ligand-bearing DNP radical moieties. ${ }^{68-70}$

We have then applied SIMPLE for probing a number of residues in the retinal binding pocket in both dark and K-states of GPR. In GPR the retinal photoisomerization site is located in an aromatic box formed by Tyr200 and Trp98/197 (Figs. 3c, 4b). Our $1{ }^{13} \mathrm{C}$ spectra show no observable ${ }^{13} \mathrm{C}$ chemical shift changes of Tyr200 upon the formation of K-state photointermediate (Fig. 4e-f). Similarly, on a GPR sample labeled at both retinal C20 methyl group and $\operatorname{Trp} \mathrm{C}_{\delta 1}\left(\left[{ }^{13} \mathrm{C}_{\delta 1}-\operatorname{Trp},{ }^{13} \mathrm{C}_{12,13,20}\right.\right.$-retinal]-GPR), we have found that the Trp residues surrounding the C20 methyl group are largely unperturbed by the retinal isomerization (Fig. S9a-c). These bulky residues therefore seem to form a rigid environment accommodating the photochemistry of retinal in GPR.

\section{Subnanometer ${ }^{13} \mathrm{C}-{ }^{13} \mathrm{C}$ distances from hNOE-initiated ${ }^{13} \mathrm{C}-{ }^{13} \mathrm{C}$ SD}

The data presented above suggest a distance-dependent ${ }^{13} \mathrm{C}-{ }^{-13} \mathrm{C}$ SD build-up kinetics (Figs. 2a, c, S8a). These observations have encouraged us to further explore the potential for a quantitative determination of ${ }^{13} \mathrm{C}-{ }^{13} \mathrm{C}$ distances. However, the well-known relayed transfer, which passes polarization between ${ }^{13} \mathrm{C}$ sites via 'shortcut' contacts in a dense ${ }^{13} \mathrm{C}$ network, often outperforms a direct SD between two distal ${ }^{13} \mathrm{C}$ sites. It therefore complicates the extraction of precise distances from the SD build-up data. Indeed, all the ${ }^{13} \mathrm{C}$ signals of Tyr200 build up at almost identical rates (Fig. S8a), indicating the rapid spin diffusion within this densely labeled spin system. Such unwanted transfers can be suppressed in a highly sparsely ${ }^{13} \mathrm{C}$-labeled protein. For example, the selective labeling of only the Tyr $\mathrm{C}^{\prime}$ sites in $\left[{ }^{13} \mathrm{C}^{\prime}-\mathrm{Tyr},{ }^{13} \mathrm{C}_{3}\right.$-retinal]-GPR allows us to reduce the ${ }^{13} \mathrm{C}$ density by about two orders of magnitude compared to the uniformly ${ }^{13} \mathrm{C}$ labeled protein (Fig. S10). This labeling scheme tethers the retinal hNOE hotspot and the nearest protein ${ }^{13} \mathrm{C}$ site as well as increases significantly the inter-Tyr distances. The $\mathrm{Tyr}{ }^{13} \mathrm{C}$ signal builds up much more slowly in $\left[{ }^{13} \mathrm{C}^{\prime}-\mathrm{Tyr},{ }^{13} \mathrm{C}_{3}\right.$-retinal]-GPR compared to those in $\left[\mathrm{U}-{ }^{13} \mathrm{C}\right.$-Tyr, ${ }^{13} \mathrm{C}_{3}$-retinal]GPR. We have then expanded to a number of other sparse ${ }^{13} \mathrm{C}$ labeling schemes of GPR, including Lys ${ }^{13} \mathrm{C}^{\prime}$, Pro ${ }^{13} \mathrm{C}^{\prime}$, Pro U- ${ }^{13} \mathrm{C}$, $\operatorname{Trp}{ }^{13} \mathrm{C} \delta 1, \operatorname{Trp}{ }^{13} \mathrm{C}^{\prime}$ and Val ${ }^{13} \mathrm{C}^{\prime}$ (Fig. 5a, Tab. S1). In all cases, we have observed hNOE-SD transfers from retinal carbons to the ${ }^{13} \mathrm{C}$-sites 
introduced in GPR (Figs. S9c, h, S11). In most cases, the protein-ligand ${ }^{13} \mathrm{C}-{ }^{13} \mathrm{C}$ SD is remarkably slower than the hNOE build-up of retinal C20 methyl groups (Tab. S1, Fig. S12). Therefore, the hNOE step does not rate-limit the ${ }^{13} \mathrm{C}-{ }^{13} \mathrm{C}$ SD here. The hNOE-SD in our samples shows a mono- or bi-exponential build-up kinetics with distinct time constants. The retinal-protein ${ }^{13} \mathrm{C}-{ }^{13} \mathrm{C}$ distances have been extracted from $\mathrm{X}$-ray crystallography structure of blue PR (4JQ6). These distances have been plotted versus the respective build-up time constants (Fig. 5b). The build-up of protein ${ }^{13} \mathrm{C}$ polarization slows down with increasing ligand-protein ${ }^{13} \mathrm{C}-{ }^{13} \mathrm{C}$ distances (Fig. 5b, Tabs. S1, S2). Theoretically the ${ }^{13} \mathrm{C}$ ${ }^{13} \mathrm{C} \mathrm{SD}$ rate is proportional to $\mathrm{r}^{-6}$ (Eq. S1b). Our experimental data can be described by this relationship, even considering a number of outliers arising from a second component in the biexponential hNOE-SD build-up kinetics in some samples (Fig. 5b grey curve, Tabs. S1, S2). The fit improves when excluding the experimental outliers. The build-up rates for two of these outliers, namely $\left[{ }^{13} \mathrm{C}^{\prime}-\mathrm{Val},{ }^{13} \mathrm{C}_{3}\right.$-retinal]-GPR (132 s) and $\left[\mathrm{U}-{ }^{13} \mathrm{C}\right.$-Pro, ${ }^{13} \mathrm{C}_{3}$-retinal]-GPR ( $8.5 \mathrm{~s}$ ) are in the range of those determined for the corresponding amino acids in frozen solution (11 - $13 \mathrm{~s}$ for proline sidechain carbons ${ }^{59}$ and $182 \mathrm{~s}$ for valine $\mathrm{C}^{\prime}$ as shown in Fig S13). They can therefore be attributed to an intra-residue hNOE build-up caused by the intrinsic dynamics (methyl reorientation or ring puckering) of these sidechains. The tryptophan side chain, which is composed by a rigid and large aromatic ring, does not show observable hNOE signal at $100 \mathrm{~K}$. However, the Trp197 C $\delta 1$ is in proximity to other methyl protons (e.g. about $3.0 \AA$ to lle192 methyl ${ }^{1} \mathrm{H}$ ). The build-up time constant of the direct methyl ${ }^{1} \mathrm{H}$ to non-methyl ${ }^{13} \mathrm{C}$ hNOE transfer (about $60 \mathrm{~s}$ ) ${ }^{59}$ matches the outlier components of our Trp data (68 $\mathrm{s}$ ) and justifies the exclusion of this component in the data fitting. The slow polarization build-up via the direct methyl ${ }^{1} \mathrm{H}$ to non-methyl ${ }^{13} \mathrm{C}$ hNOE transfer is also outperformed by the more efficient ${ }^{13} \mathrm{C}-{ }^{13} \mathrm{C} \mathrm{SD}$ as shown by our data analysis. Additional analysis of the robustness of our data interpretation is provided in the $\mathrm{SI}$. The observation of a strong correlation between ${ }^{13} \mathrm{C}-{ }^{13} \mathrm{C}$ distances and SD dynamics $\left(r^{-6}\right)$, in contrast to a weakly correlated $r^{-3}$ pattern typical to a dense ${ }^{13} \mathrm{C}$ network further validates that the relayed transfer is efficiently inhibited in these highly sparse ${ }^{13} \mathrm{C}$ labeling schemes ${ }^{71-72}$. The maximum deviation between the distances determined from a GPR structural model and those back-calculated from the SD data is below $0.4 \AA$ (Tab. S2). Here we have established a new prototype ${ }^{13} \mathrm{C}-{ }^{13} \mathrm{C}$ distance measurement method bridging the subnanometer gap between conventional ssNMR methods (ca. 1-6 $\AA$ ) and popular dipolar EPR/FRET ( $>1 \mathrm{~nm}$ ) spectroscopy. Both our approach and FRET share the same distance-dependence of the transition probability of dipolar-driven processes 
(Eq. S1, S2). The polarization transfer from the methyl ${ }^{13} \mathrm{C}$-carbon to other ${ }^{13} \mathrm{C}$-sites comprises some analogy to the well-known donor-reporter configuration in FRET. Since in our approach the polarization "donor" and "reporter" are both ${ }^{13} \mathrm{C}$ nuclei, this minimally sized labeling eliminates problems caused by bulky labels used for FRET and dipolar EPR spectroscopy. Our approach enables the measurement of ${ }^{13} \mathrm{C}-{ }^{13} \mathrm{C}$ distances in the subnanometer range as long as a mono-exponential hNOE-SD build-up is observed. The possible ambiguity arising from biexponential hNOE-SD build-up kinetics remains to be further explored.

${ }^{13} \mathrm{C}-{ }^{13} \mathrm{C}$ SD or in general ${ }^{13} \mathrm{C}-{ }^{13} \mathrm{C}$ dipolar recoupling is one of the cornerstones of the contemporary biological SSNMR. Most of the previous works on this direction have focused on uniformly labeled or partially diluted ${ }^{13} \mathrm{C}$ spin systems, therefore still suffer considerably from the relayed transfers. It has been shown that in such spin systems the spectroscopic selection of a subset of ${ }^{13} \mathrm{C}$ spins can mimic a sparse distribution of the active spins and therefore alleviate the relayed transfer ${ }^{73-75}$ These elegant methods have pushed the upper-limit of the ${ }^{13} \mathrm{C}-{ }^{13} \mathrm{C}$ distance measurement to over $5 \AA .{ }^{73-75} \mathrm{In}$ our approach, the direct implementation of highly sparse ${ }^{13} \mathrm{C}$-labeling schemes strongly suppresses the relayed transfer and further pushes this distance upper-limit closer to one nanometer. We have also noticed that Zilm and coworkers have proposed a relevant and user-friendly approach for long ${ }^{13} \mathrm{C}-{ }^{13} \mathrm{C}$ distance measurement between a methyl group and the backbone $C^{\prime}$ sites ${ }^{76}$. In their proposal the methyl group would serve as a relaxation sink rather than a polarization source and the enhanced relaxation of $C^{\prime}$ polarization via ${ }^{13} \mathrm{C}-{ }^{13} \mathrm{C}$ SD with methyl ${ }^{13} \mathrm{C}$ could contain distance information. The proposed method is based on the decay of the ${ }^{13} \mathrm{C}$ ' signals and would have to deal with those distal ${ }^{13} \mathrm{C}$ ' signals that decay slowly and remain in the overlapped carbonyl region. In our approach, the nonmethyl ${ }^{13} \mathrm{C}$ site (e.g. ${ }^{13} \mathrm{C}$ ), which is in dipolar cross-talk with the methyl hNOE hotspot via the SD process, show a build-up kinetics of enhanced polarization in a selective fashion.

Our approach on distance determination has immediately allowed us to probe the retinal-protein architecture in the K-photointermediate of GPR. Since the Trp-Tyr box surrounding the retinal is unperturbed by the retinal isomerization, we then turned to Lys231 on the helix $G$ that binds covalently to the retinal cofactor. We have examined the distance between the retinal methyl $\mathrm{C} 20$, that is close to the retinal photoisomerization site, and the C' of Lys231, the anchoring site of the retinal-Lys moiety on GPR. Our measurement shows that the ${ }^{13} \mathrm{C}-{ }^{13} \mathrm{C}$ SD rate between these two sites is barely affected upon the formation of the K-state photointermediate (Fig. S14). The small differences 
could be attributed to the differences in the hNOE build-up times of the C20 methyl group in two states (Fig. 3a). Our SD data show that the Lys $C^{\prime}$ is unaffected upon the formation of the K-state, which coincides with the unchanged Lys C' chemical shift (Fig. S9c, d). This indicates that the propagation of the initial structural perturbation by retinal isomerization does not reach the helix $\mathrm{G}$ in the K-state.

\section{Mechanistic insights into the early molecular events of GPR photocycle}

Our new NMR data presented above offers new insights into the early molecular event of GPR photocycle.

First, hNOE build-up kinetics shows that retinal C20 methyl group, which is next to the retinal $\mathrm{C} 13=\mathrm{C} 14$ isomerization site in GPR, is engaged in tighter packing against its protein environment upon the K-state formation. In microbial rhodopsins this methyl group is generally believed to be a key player in the early phases of photocycles. ${ }^{77-79}$ Here our data offers the direct biophysical evidence for the involvement of retinal C20 methyl group in GPR photocycle.

Second, our SIMPLE approach shows that bulky residues Tyr200 (helix F) and Trp98/197 (helix C/F) do not respond to retinal isomerization, revealing a rigid aromatic box accommodating the retinal photochemistry. This observation has been extended to the retinal-anchoring residue Lys231 (helix $\mathrm{G}$ ) by exploring retinal-Lys backbone distance via ${ }^{13} \mathrm{C}-{ }^{13} \mathrm{C}$ SD kinetics. Our data indicate that the structural impact of retinal isomerization does not propagate to helix G. Both X-ray crystal structures of a GPR homologue (4JQ6) $)^{56}$ and the recent MD simulations ${ }^{80}$ point to a closer contact between retinal C20 methyl group and the sidechain of Leu105 (helix C) upon K-state formation. We have further examined the propagation of this initial contact using SIMPLE approach (Fig. S9d-f). Similar to Lys 231, our data largely excludes the structural perturbation on the backbone of Leu105. These molecular features are distinct from those of BR, in which many protein sites are perturbed upon K-state formation ${ }^{24,81-82}$. Interestingly, even the protonated Schiff base (pSB) site in GPR remains largely unperturbed by retinal photoisomerization, ${ }^{51,83}$ which is in drastic contrast to a number of other microbial rhodopsins ${ }^{15,22,83}$. Here, the distinct and rather restricted protein structural perturbation pattern upon GPR K-state formation echoes the recently discovered complexity and diversity of protein responses to retinal photoisomerization in microbial rhodopsins. ${ }^{23-24,82,84}$ 


\section{Conclusions and perspectives}

In this work we have presented a new DNP-enhanced methyl SSNMR spectroscopic toolkit for investigating the structure, dynamics and molecular interactions in biomacromolecular complexes. Our approaches integrate seamlessly CE DNP, methyl ${ }^{1} \mathrm{H}-$ ${ }^{13} \mathrm{C}$ hNOE, ${ }^{13} \mathrm{C}_{\text {methyl- }}{ }^{13} \mathrm{C}_{\text {non-methyl }} \mathrm{SD}$ and sparse isotope labeling schemes. Here hNOE build-up kinetics of methyl groups reports local protein-ligand packing in different protein functional states. The coupling of methyl hNOE with ${ }^{13} \mathrm{C}-{ }^{13} \mathrm{C}$ SD in the sparse ${ }^{13} \mathrm{C}$ spin system forms a new NMR approach (SIMPLE) for selective detection of nearby interacting residues. In this way, subnanometer distances can be accessed that have been out of reach of other biophysical methods. Considering that 1D SIMPLE spectra appear straightforward to interpret and distance extraction from hNOE build-ups does not require any specialized data fitting, our work could therefore create a starting point for developing user-friendly NMR tools. We have demonstrated that our approach can be directly applied to the complex membrane protein GPR, providing immediately novel insight into the Kstate formation, which will support the structural determination/refinement of the GPR photointermediates in the future. We expect that our methods will support researchers in biophysics, structural biology, chemistry, (bio)materials and drug development. The immediate applications will include (but are not limited to) biomacromolecule-ligand interactions and in-cell detection of key binding-site residues.

\section{Materials and methods}

\section{DNP ssNMR sample preparation}

${ }^{13} \mathrm{C}_{10-18}$-retinal was synthesized as described before. ${ }^{85}{ }^{13} \mathrm{C}_{12,13,20}$ - retinal was prepared from ${ }^{13} \mathrm{C}_{12,13,20}$-vitamin A palmitate (Buchem B.V., The Netherlands) following procedures published previously. ${ }^{86}$

Wild-type GPR (UniProt Q9F7P4) from y-proteobacterium EBAC31A08 (SAR86 clade) was expressed, purified and reconstituted into liposome as described previously. 14, 51 For residue-type selective isotope labeling, one of the isotope-labeled amino acids (leucine $115 \mathrm{mg}$, tyrosine $85 \mathrm{mg}$, proline $50 \mathrm{mg}$, valine $115 \mathrm{mg}$, phenylalanine $65 \mathrm{mg}$, lysine $105 \mathrm{mg}$ or indole $50 \mathrm{mg}$ for half liter culture) or amino acid mixture $\left(\mathrm{U}-{ }^{13} \mathrm{C}\right.$ Tyr 85 $\mathrm{mg}$ and ${ }^{15} \mathrm{~N}$ Pro $50 \mathrm{mg}$ for half liter culture) were supplied in M9 minimal medium when the cell density OD reached 0.4 . The cells were further incubated at $37^{\circ} \mathrm{C}$ for about $40-60$ min until the OD reached 0.6 for IPTG induction. An excess amount of ${ }^{13} \mathrm{C}_{12,13,20-}$ or ${ }^{13} \mathrm{C}_{10}$ 18 -retinal ${ }^{85}$ was added into the cell membrane suspension after the cell disruption and the 
mixture was incubated at room temperature for $1 \mathrm{~h}$. GPR was reconstituted into the DMPC/DMPA (9:1 mole/mole) liposomes (200 $\mu \mathrm{m}$ diameter) at a lipid-to-protein ratio (LPR) of 1:2 (weight/weight). This LPR was chosen in order to maximize the amount of protein that could be packed into a MAS rotor while maintaining a suitable sample transparency for efficient light penetration needed for trapping the K-state. The reconstituted proteoliposomes containing about 8 - $10 \mathrm{mg}$ GPR were pelleted using an ultracentrifuge (ca. $1.4 \times 10^{5} \mathrm{~g}$ ) and were soaked overnight at $4^{\circ} \mathrm{C}$ in $200 \mu \mathrm{L}$ DNP solution (20 mM AMUPol). For all hNOE-related experiments, we used a fully-protonated DNP solution containing $30 \%$ glycerol and $70 \%$ NMR buffer $\left(50 \mathrm{mM}\right.$ Tris, $5 \mathrm{mM} \mathrm{MgCl}_{2}, \mathrm{pH}=9$ at $\left.4^{\circ} \mathrm{C}\right)$.

\section{DNP-Enhanced MAS ssNMR experiments}

All DNP-enhanced MAS ssNMR experiments were performed on a Bruker Avance II spectrometer operating at 400.197 MHz ( ${ }^{1} \mathrm{H}$ Larmor frequency, 9.40 T). The spectrometer was coupled to a CPI (Communication and Power Industries) gyrotron (microwave frequency $263.580 \mathrm{GHz}$ ) via corrugated waveguides. The microwave power directed into the MAS stator was estimated to be above $10 \mathrm{~W}$. The NMR samples were packed into 3.2 $\mathrm{mm} \mathrm{ZrO}_{2}$ rotors and were sealed by Vespel caps. All ssNMR experiments were carried out under $8 \mathrm{kHz}$ MAS unless specified otherwise. The sample temperature was maintained by the cooling gas as well as the cold bearing and driving gas flows. For experiments at elevated temperatures, all three cryogenic nitrogen gas flows were heated and the driving and/or bearing gas flow was reduced in order to reach the proper balance between MAS stability and the effective temperature as read out on the spectrometer. In particular for the experiments above $150 \mathrm{~K}$, the cooling gas was still set to below $150 \mathrm{~K}$ in order to bypass the interlock for the NMR probe protection. The ${ }^{1} \mathrm{H}$ DNP-enhancements were determined indirectly via ${ }^{1} \mathrm{H}-{ }^{13} \mathrm{C}$ experiments using $3 \mathrm{~s}$ interscan delays.

The ${ }^{1} \mathrm{H}-{ }^{13} \mathrm{C}$ hNOE-related spectra in this work were acquired by using the pulse program shown in Fig $1 \mathrm{~b}$. The $\pi / 2$-pulse trains composed by 16 repeats of ${ }^{1} \mathrm{H}(100 \mathrm{kHz})$ and ${ }^{13} \mathrm{C}(62.5 \mathrm{kHz})$ pulses with $5 \mathrm{~ms}$ interval were applied for destroying the residual magnetizations. The build-up times correspond to the time span between the time point $A$ and $\mathrm{B}$. The A-to-B delays without applying any pulses permits the $\mathrm{hNOE} /{ }^{13} \mathrm{C}-{ }^{13} \mathrm{C}$ SD buildups. For removing the background signals including those from the direct ${ }^{13} \mathrm{C}$ hyperpolarization, a ${ }^{1} \mathrm{H}$ T-pulse $(100 \mathrm{kHz})$ trains composed by the pulses tethered by a time delay of $125 \mathrm{~ms}$ were applied during the A-to-B delay. The A-to-B time during were 
varied by adjusting directly the delay length (without ${ }^{1} \mathrm{H}$ pulses) or by setting the proper number of ${ }^{1} \mathrm{H}$ saturation pulse repeats. The ${ }^{13} \mathrm{C}$ FIDs were recorded after the ${ }^{13} \mathrm{C} \pi / 2$ reading pulse following the A-to-B delay under $100 \mathrm{kHz}$ SPINAL64 ${ }^{1} \mathrm{H}$ decoupling. ${ }^{87}$ The final ${ }^{13} \mathrm{C}$ spectra were obtained by subtracting the spectra acquired with and without the ${ }^{1} \mathrm{H}$ saturation pulses covering the same build-up times. For the convenience of readers, the phase of the spectra were readjusted by $180^{\circ}$ to yield positive signals (Fig 2). According to our experiences, as long as the same type of (fully hydrated) proteoliposome samples, NMR rotor and the same temperature were used, neither the tuning, matching of the NMR probehead nor the ${ }^{1} \mathrm{H}$ and ${ }^{13} \mathrm{C}$ pulse parameters needed to be readjusted between different measurements. The sensitivity of these experiments depends on the sample amount, K-state population, build-up efficiency in a given A-to-B delay and other factors such as DNP enhancement factor. The measurement time can be approximated by the product of the number of scans and the duration of A-to-B delay. The 1D hNOE spectra shown in Fig. 2 were acquired on a small quantity of protein (ca. 2-3 mg or 65-100 $\mathrm{nmol}$ ) in order to ensure a high degree of light penetration into the sample. In total 4096 scans (2048 scans with and 2048 scans without ${ }^{1} \mathrm{H}$ saturation pulses) were accumulated for each 1D hNOE spectra in Fig. 2, which correspond to the total measurement time of about $1 \mathrm{~h}$. The hNOE spectra for deriving the build-up time constant above $140 \mathrm{~K}$ in Fig. 3a were collected on a fully packed rotor containing about 8-10 mg GPR due to the lower sensitivity at higher temperatures. The SIMPLE spectra shown in Fig. $4 \mathrm{e}$ and Fig. $4 \mathrm{f}$ were recorded on small quantity of protein (ca. 2-3 mg) and a rather short A-to-B delay (1 s) was used to prevent further polarization transfer to distal sites. Therefore, more scans were required for these experiments $(10240 * 2$ or about $6 \mathrm{~h}$ for Fig. $4 \mathrm{e}$ and $24576 * 2$ or about $14 \mathrm{~h}$ for Fig. $4 \mathrm{f}$ ). The spectra for deriving ${ }^{13} \mathrm{C}-{ }^{13} \mathrm{C}$ SD rates (Fig. S11-S12 and Tab. S1) were acquired on 8-10 mg GPR with various A-to-B delays. Typically, 1-4 h were required for each data point in Fig. S12. The measurement time for determining one ${ }^{13} \mathrm{C}-$ ${ }^{13} \mathrm{C}$ SD rate was between 1-4 days. The ${ }^{1} \mathrm{H} \mathrm{T}_{1}$ was measured via a standard saturationrecovery experiment with the same setups used in a previous work. ${ }^{88}$

The ${ }^{13} \mathrm{C}-{ }^{-15} \mathrm{~N} \mathrm{~N}(\mathrm{CO}) \mathrm{CX} 2 \mathrm{D}$ NMR spectrum was acquired on a U- ${ }^{13} \mathrm{C}$ Tyr and ${ }^{15} \mathrm{~N}$ Pro pairwise-labeled GPR sample using the standard setting up. The ${ }^{13} \mathrm{C}-{ }^{13} \mathrm{C}$ SD of $100 \mathrm{~ms}$ was used. The spectrum was acquired with 2048 (F2) by 16 (F1) points sampling spectral windows of $405 \mathrm{ppm}\left(\mathrm{F} 2,{ }^{13} \mathrm{C}\right)$ and $74 \mathrm{ppm}\left(\mathrm{F} 1,{ }^{15} \mathrm{~N}\right)$. The 2D spectrum was processed with an 8192 (F2) by 1024 (F1) matrix. A Gaussian (lb = -40 Hz, gb = 0.1) and Qsine (ssb $=2$ ) window function were used for processing the F2 and F1 dimension respectively. All 
the ${ }^{13} \mathrm{C}$ chemical shifts were reference to DSS indirectly via an alanine crystalline powder sample and all ${ }^{15} \mathrm{~N}$ chemical shifts were referenced to liquid ammonia indirectly using the gyromagnetic ratios.

The $1 \mathrm{D}{ }^{1} \mathrm{H}-{ }^{13} \mathrm{C} C P$ spectra with and without DQF were acquired using standard pulse programs. ${ }^{13} \mathrm{C}$-double quantum filter experiments (DQF-experiments) were obtained using the POST-C $7^{89}$ sequence for double quantum excitation and reconversion at $0.5 \mathrm{~ms}$. In situ sample illumination under DNP-ssNMR conditions was carried out using a set as described before. ${ }^{15,51}$ Briefly, light from a high-power blue light LED (ca. $50 \mathrm{~W}$, central frequency $470 \mathrm{~nm}$, Mightex System) was directly coupled via a liquid light guide (300 $650 \mathrm{~nm}$ ) and an optical fiber into the cryo-MAS stator of the DNP ssNMR probehead. Samples as a thin layer of hydrated proteoliposomes were distributed over the inner wall of the light-transparent $3.2 \mathrm{~mm}$ sapphire rotors. MAS rotors were spun at $8 \mathrm{kHz}$ at about $100-110 \mathrm{~K}$ and illuminated for 60 to $90 \mathrm{~min}$. The dark-to-K conversion can be monitored by DQF $1 \mathrm{D}{ }^{13} \mathrm{C}$ spectra. A full conversion cannot be reached presumably due to the limited light intensity/penetration. Once the K-photointermediate was adequately accumulated, the light source was turned off and the K-state GPR trapped at the cryogenic temperature was subjected directly to DNP-enhanced ssNMR experiments.

\section{Data analysis}

For extracting build-up time constants, ${ }^{13} \mathrm{C}$ signals of $1 \mathrm{D}$ hNOE(-SD) spectra were analyzed by manual peak integration in Bruker TopSpin 3.5. These integral intensities were then fitted in Origin 8.5. The internuclear distances were determined from the crystal structure of blue PR, a GPR homologue (PDB 4JQ6, resolution $2.3 \AA$ ) in PyMol. More details about data fitting can be found in SI. Fig. 3b was plotting using Mathematica and more details about the generation of this curve can be found in SI.

\section{QM/MM calculations of the potential energy surface (PES) of retinal C20 methyl group in GPR}

Based on the structural model of GPR created from the blue PR structure (4JQ6), 12 orientations of the retinal C20 methyl group were created by varying the retinal $\mathrm{C} 12-\mathrm{C} 13-$ $\mathrm{C} 20-\mathrm{H}$ dihedral angle in a step of 10 degrees. The energy calculation of each of these single point structures was performed at the B3LYP/cc-pVDZ level by Gaussian 09 program. ${ }^{90}$ For each calculation, the QM region contained the retinal, $\mathrm{pSB}$, the linked Lys231 $\mathrm{C} \varepsilon$ atom and the side chain of W197. The dangling bond was capped by a 
hydrogen atom. We have noticed that the energy barrier of C20 methyl reorientation in ground-state GPR is largely unaffected by including W197 in the QM region. The other residues were treated as background charges and the polarized protein-specific charge (PPC) model was used in our calculations. The PPC charges were fitted to electrostatic potentials using fragment quantum mechanical calculation of the protein. The molecular fractionation with conjugate caps scheme by incorporating the Poisson-Boltzmann solvation model (MFCC-PB) ${ }^{90-94}$ was applied to iteratively fit the atomic charges. The first step of the iterative procedure was to solve the electronic structure of each individual amino acid fragment at the B3LYP/6-31G* level. In each fragment calculation, the rest atoms outside the QM region were considered as the background charges. The retinal was considered as part of the side chain. In the second step, the standard two-stage RESP method ${ }^{95}$ was used to fit the partial atomic charges of the entire system. The PB solver Delphi ${ }^{93}$ was employed to calculate the induced charges on the solute-solvent interface, which was defined using a probe radius of $1.4 \AA$. The grid density was set to 4.0 grids $/ \AA$ in numerically solving the PB equation with a solvent dielectric constant of 80 . The updated atomic charges were passed to the next interaction of charge fitting. This fitting procedure was repeated iteratively until the corrected reaction field energy calculated with Delphi converged and the variations of point charges were smaller than a given threshold.

\section{Acknowledgements}

Clemens Glaubitz and Xiao He thank the National Natural Science Foundation of China (NSFC, Grant No. 21761132022) and DFG 391643887 for a collaborative research grant. This work was funded by DFG/SFB807 "Transport and communications across membranes" (to CG). DNP experiments were enabled through an equipment grant provided by DFG (GL307/4-1) and Cluster of Excellence Macromolecular Complexes Frankfurt (to CG). Björn Corzilius is supported by DFG via grants CO802/2 (Emmy Noether program) as well as CO802/4-1. Xiao He acknowledges the NSFC (Grant No. 21922301, and 21673074), the Ministry of Science and Technology of China (Grant No. 2016YFA0501700), Shanghai Municipal Natural Science Foundation (Grant No. 18ZR1412600), youth top-notch talent support program of Shanghai, and the NYU-ECNU Center for Computational Chemistry at NYU Shanghai for the financial supports. We also thank the Supercomputer Center of East China Normal University (ECNU Multifunctional Platform for Innovation 001) for providing the computational time. Jiafei Mao thanks Goethe University of Frankfurt am Main for the supports via FOKUS program. Ingrid 
Weber and Johanna Becker-Baldus are acknowledged for their constant technical supports. Orawan Jakdetchai and Johanna Becker-Baldus are acknowledged for the stimulating discussions. Jiafei Mao dedicates this contribution to the late Prof. Ivano Bertini for his inspiration and perspective on pursuing new NMR methodologies for biological applications.

Supporting Information: GPR photocycle (S1); ${ }^{13} \mathrm{C}-{ }^{13} \mathrm{C}$ PDSD of methyl region of $\left[{ }^{13} \mathrm{C}_{10}-\right.$ 18-retinal]-GPR (S2); DNP sample preparation conditions (S3); additional hNOE build-up curves (S4); Saturation recovery data (S5); hNOE-SD build-up of retinal (S6); SIMPLE control experiments (S7); hNOE-SD build-up of Tyr (S8); ${ }^{13} \mathrm{C}$ spectra of selectively labeled GPR (S9); Spin density of sparsely labeled GPR samples (S10); hNOE-SD build-up of selectively labeled GPR samples (S11); hNOE-SD build-up kinetics of GPR and model compounds (S12-S14); Supplementary Material and Methods (Supporting information for Fig 3c; Distance dependence laws (Eq. S1, S2); Supporting information SD kinetics); Summary of build-up time constants (Tab. S1); Analysis of internuclear distances (Tab. S2). This material is available free of charge via the Internet at http://pubs.acs.org. 
Figures and Legends

a

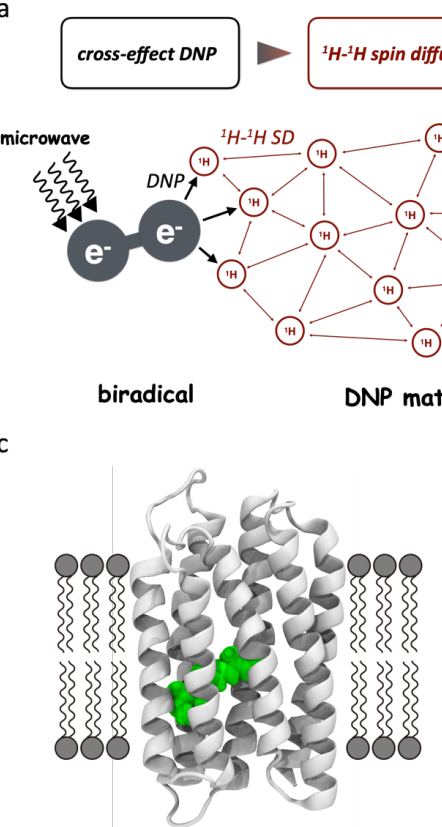

b
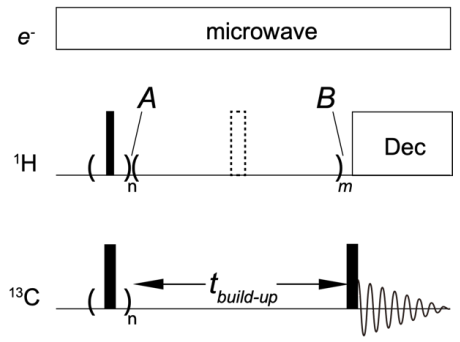

e
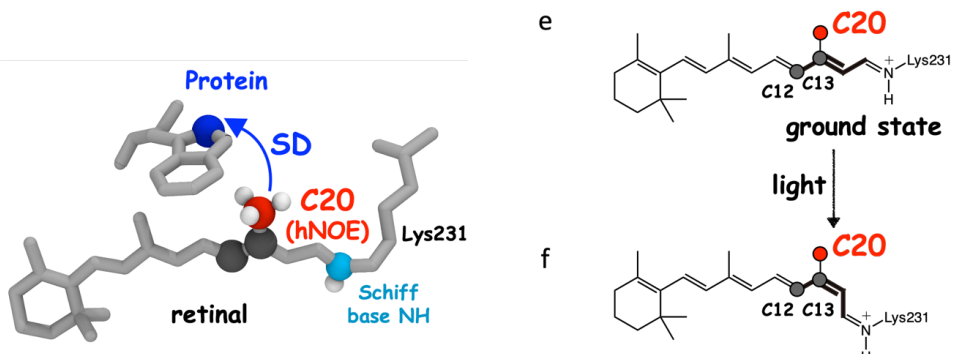

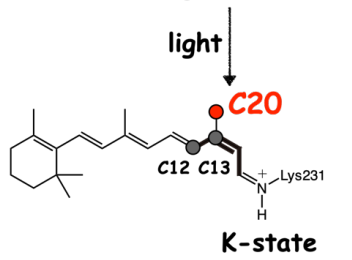

Fig 1. Introduction to spin dynamics. NMR experiments and membrane protein targeted in this work. (a) Methyl ${ }^{13} \mathrm{C}$ hyperpolarization is created via a relay of cross-effect (CE) DNP, ${ }^{1} \mathrm{H}-{ }^{1} \mathrm{H}$ spin diffusion (SD) and hNOE. Further magnetization transfer from methyl ${ }^{13} \mathrm{C}$ to other ${ }^{13} \mathrm{C}$ takes place via ${ }^{13} \mathrm{C}-{ }^{13} \mathrm{C}$ SD. (b) NMR pulse sequence used here as described by Daube et al. ${ }^{28}$. After the initial ${ }^{1} \mathrm{H}$ and ${ }^{13} \mathrm{C} \pi / 2$ pulse trains (black) that destroy the residual magnetization, ${ }^{1} \mathrm{H}-{ }^{13} \mathrm{C}$ magnetization transfer occur during tbuild-up (polarization delay) via hNOE followed by ${ }^{13} \mathrm{C}-{ }^{13} \mathrm{C}$ SD. The signal is detected via a ${ }^{13} \mathrm{C}$ reading pulse. The resulting spectra contain signals from both the direct (DNP) and indirect (hNOE) ${ }^{13} \mathrm{C}$ polarization. A train of ${ }^{1} \mathrm{H}$ m pulses (dashed bar) during tbuild-up, cancels the signal contributions from the hNOE. ${ }^{28}$ Difference spectra obtained with and without these ${ }^{1} \mathrm{H} \pi$ pulses therefore show pure hNOE signals. (c) Green proteorhodopsin (GPR) embedded in lipid bilayer with a methyl-group-labeled retinal chromophore and ${ }^{13} \mathrm{C}$-labeled residues (d) is used to demonstrate the magnetization transfer shown in (a). (e) Upon light illumination, all-trans retinal in GPR switches to 13-cis (f) forming the GPR K-state. 


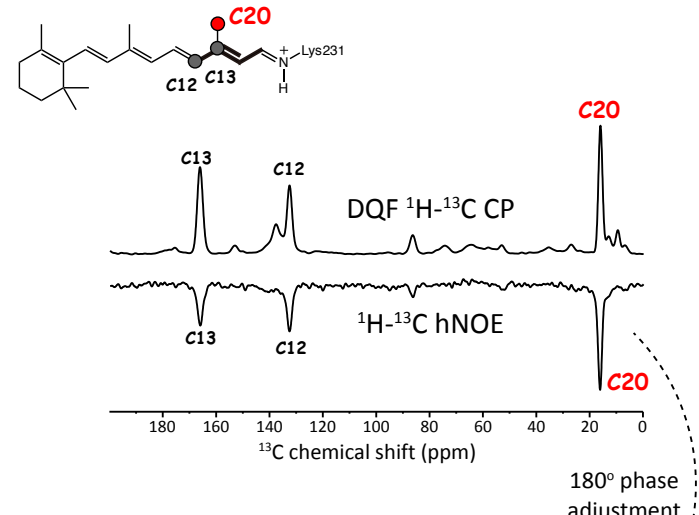

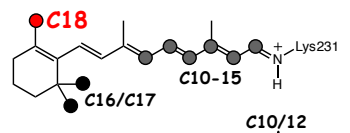

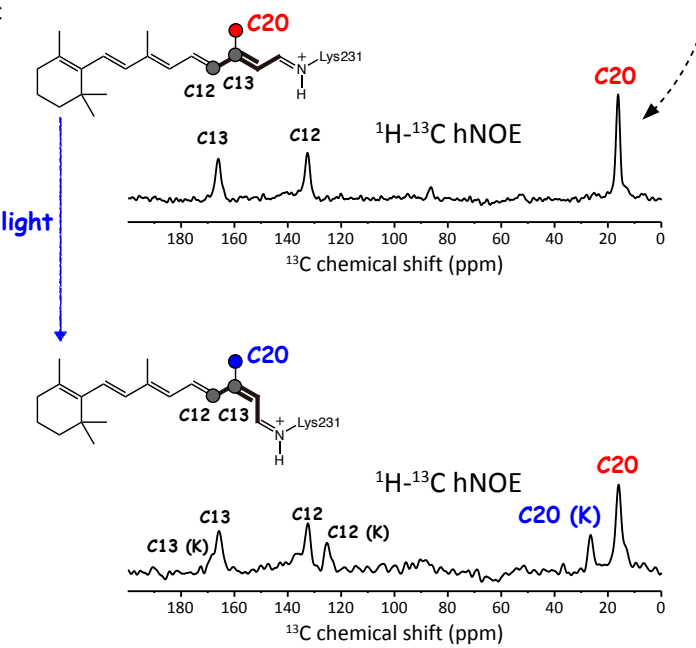

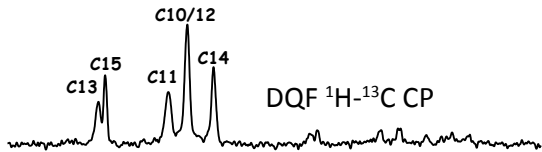
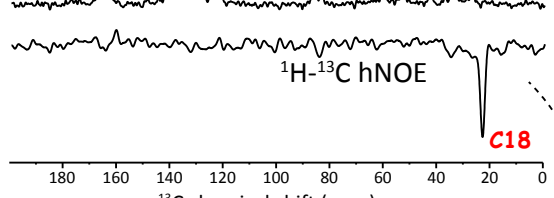

d

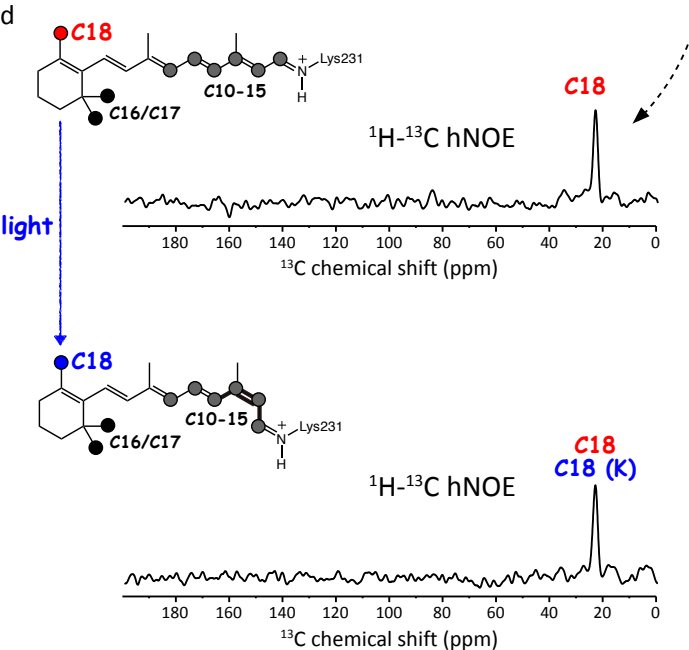

Fig. 2: DNP-enhanced methyl ${ }^{1} \mathrm{H}-{ }^{13} \mathrm{C}$ hNOE spectra of $\left[{ }^{13} \mathrm{C}_{12,13,20}\right.$-retinal]- and $\left[{ }^{13} \mathrm{C}_{10-18}\right.$-retinal]GPR. (a) For $\left[{ }^{13} \mathrm{C}_{12,13,20}\right.$-retinal]-GPR, the $\mathrm{C} 20$ methyl signal of negative intensity is detected, indicating the presence of hNOE/indirect magnetization transfer. Via ${ }^{13} \mathrm{C}-{ }^{13} \mathrm{C} S \mathrm{SD}, \mathrm{C} 20$ hyperpolarization further transfers to neighboring $\mathrm{C} 12$ and $\mathrm{C} 13$, which leads to the negative signal intensity of these two non-methyl carbons. For comparison, a ${ }^{13} \mathrm{C}-\mathrm{DQF}$ spectrum is shown. (b) For $\left[{ }^{13} \mathrm{C}_{10-18}\right.$-retinal]-GPR only the signal of $\mathrm{C} 18$ can be observed. In contrast to (a) none of the other carbons seen in the DQF spectrum can be detected, since magnetization transfer via SD occur much slower than in (a). For simplicity, all subsequent hNOE spectra are plotted with positive intensities. (c) Upon light illumination at $110 \mathrm{~K}$, the K-photointermediate of GPR is generated and cryo-trapped. The hNOE spectrum of $\left[{ }^{13} \mathrm{C}_{12,13,20-r e t i n a l]-G P R}\right.$ shows signals of both dark- and Kstate. In particular, the $\mathrm{C} 20$ methyl signal of the K-state shows a drastic downfield shift compared to that of the dark-state, allowing the methyl signals in two states to be well-resolved. (d) In contrast to $\mathrm{C} 20$, the $\mathrm{C} 18$ methyl signal shows no observable shift passing from dark- to K-state with the same experimental procedure used for (c). 

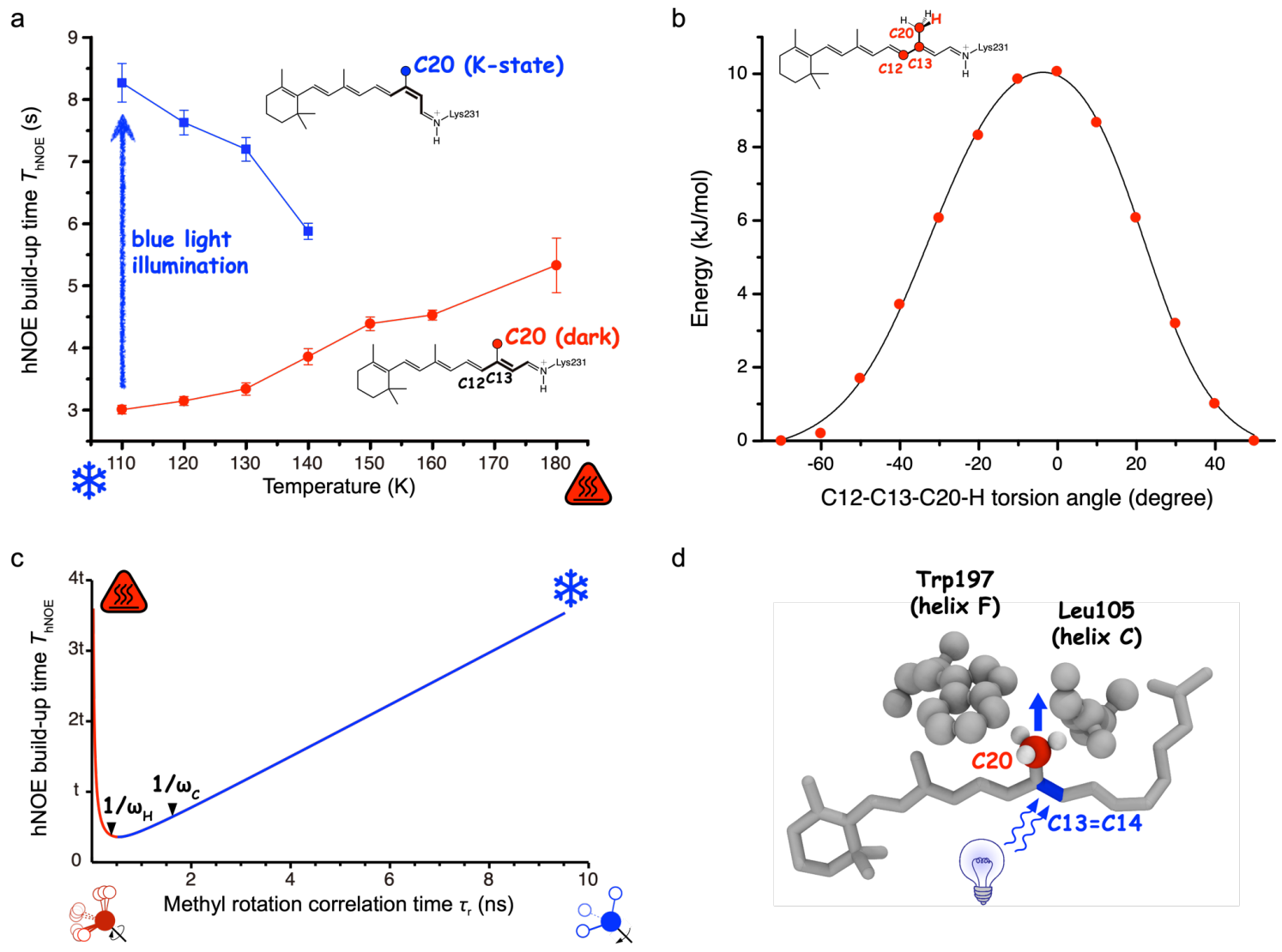

d

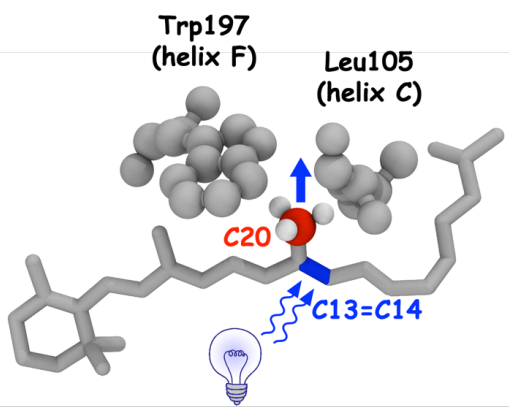

Fig. 3: hNOE build-up kinetics of the retinal C20 methyl group reports the local protein-retinal packing in GPR. (a) C20 hNOE build-up kinetics as a function of temperature in dark- and K-state GPR. Opposite trends are observed for both cases. (b) Calculated potential energy surface (PES) of retinal C20 in dark-state GPR. The relative energy is plotted as a function of the methyl group rotation expressed by the $\mathrm{C} 12-\mathrm{C} 13-\mathrm{C} 20-\mathrm{H}$ torsion angle. The maximum amplitude provides the rotation energy barrier. The slight asymmetry in the Gaussian-like shape is possibly caused by the asymmetric protein environment as shown in (d). (c) Qualitative bimodal relationship between hNOE build-up time constants and methyl reorientation correlation times. When the methyl reorientation rate approaches the range of ${ }^{1} \mathrm{H} /{ }^{13} \mathrm{C}$ Larmor frequencies, hNOE build-up occurs most rapidly. In the regime of high $\tau_{c}$ (blue branch), slower methyl reorientation leads to a slower hNOE build-up. In contrast, in the low $\tau_{c}$ regime (red branch), faster methyl reorientation would lead to a slower hNOE build-up. The hNOE build-up kinetics of C20 in dark state GPR therefore fits into the 'fast' and that of K-state matches the 'slow' branch (see main text and SI for further details). (d) As suggested by the ground-state structural model of GPR, photoisomerization of retinal $C 13=C 14$ double bond (shown in blue) can potentially cause steric clashing of C20 methyl group (shown in red) against surrounding bulky residues. 
a

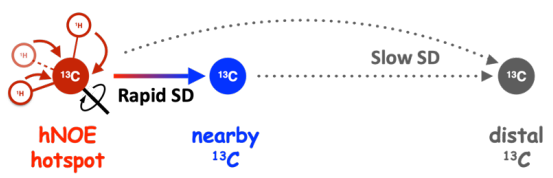

b

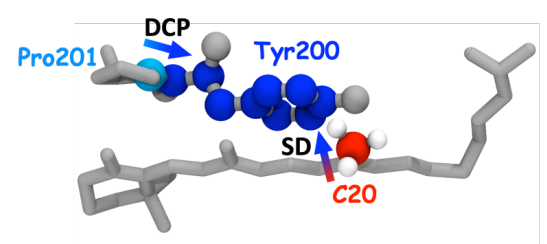

${ }^{C} D Q F{ }^{1} H-{ }^{13} C C P$

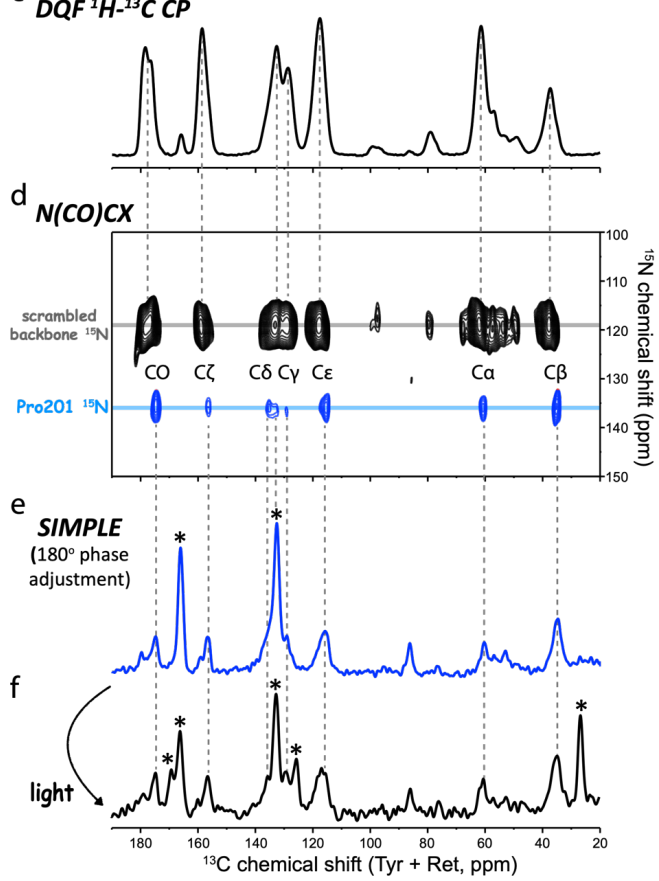

Fig. 4: $1 \mathrm{D}$ SIMPLE experiment enlightens selectively Tyr200 in GPR. (a) Sparse ${ }^{13} \mathrm{C}$ labeling permits ${ }^{13} \mathrm{C}$ hyperpolarization from the methyl hNOE site to be delivered to nearby carbons via ${ }^{13} \mathrm{C}$ ${ }^{13} \mathrm{C}$ SD. The hNOE process has to be fast enough so that it is not rate-limiting the following SD step. (b) Signals of Tyr200 are selected via pair labelling with Pro201 ([U-13 C-Tyr, ${ }^{15} \mathrm{~N}-$ Pro]-GPR) via a conventional $\mathrm{N}(\mathrm{CO}) \mathrm{CX}$ experiment or through SIMPLE via retinal carbon $\mathrm{C} 20\left(\left[\mathrm{U}-{ }^{13} \mathrm{C}-\mathrm{Tyr}\right.\right.$,

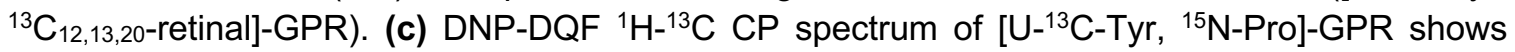
overlapping Tyr ${ }^{13} \mathrm{C}$ signals without site resolution. (d) DNP- $\mathrm{N}(\mathrm{CO}) \mathrm{CX}$ spectrum of $\left[\mathrm{U}-{ }^{13} \mathrm{C}-\mathrm{Tyr},{ }^{15} \mathrm{~N}\right.$ Pro]-GPR visualizes the unique Tyr200 $\left({ }^{13} \mathrm{C}\right)$-Pro201 $\left({ }^{15} \mathrm{~N}\right)$ pair (blue). Due to ${ }^{15} \mathrm{~N}$ scrambling of Pro in $E$. coli resulting in sparse ${ }^{15} \mathrm{~N}$ amide labelling of some residues, additional correlations with other

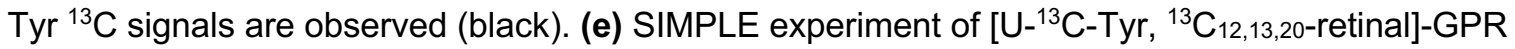
highlights selectively ${ }^{13} \mathrm{C}$ signals of nearby Tyr200 as the signals match those resolved on 2D $\mathrm{N}(\mathrm{CO}) \mathrm{CX}$ spectrum in (d). The * symbols marks signals of retinal carbons C12 and C13. (f) SIMPLE

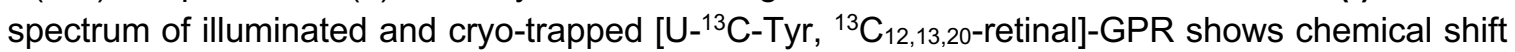
changes of retinal carbons due to the trans-cis isomerization and formation of the K-state. Tyr200 ${ }^{13} \mathrm{C}$ chemical shifts remain unperturbed. 
a

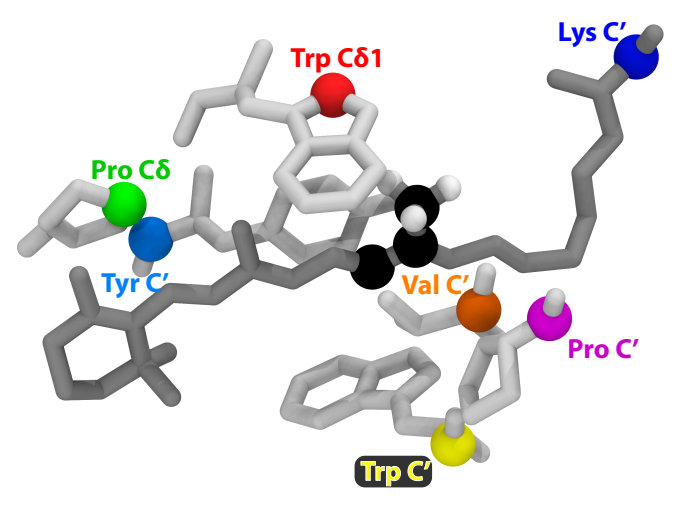

b

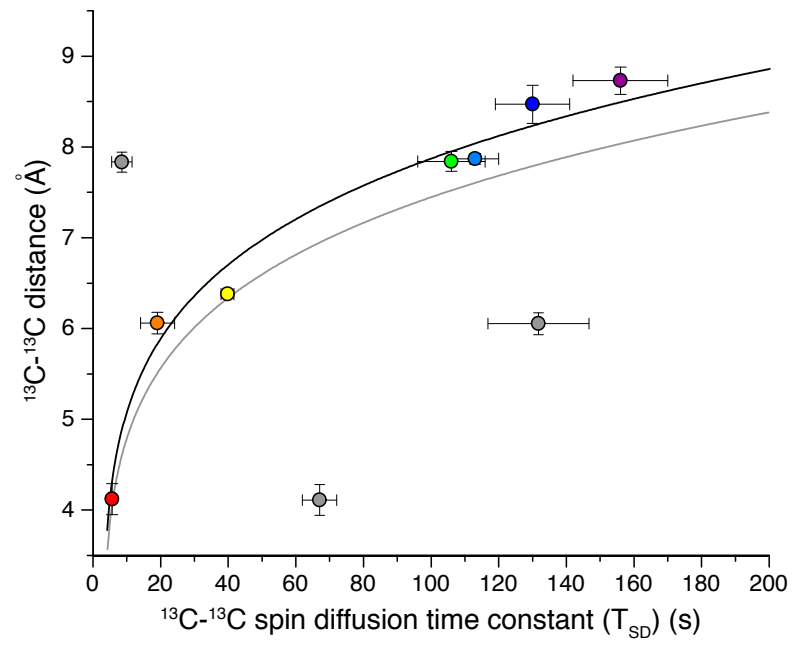

Fig. 5: Accessing subnanometer ${ }^{13} \mathrm{C}-{ }^{13} \mathrm{C}$ distances between retinal $\mathrm{C} 20 \mathrm{hNOE}$ hotspot and carbons in adjacent residues in sparsely ${ }^{13} \mathrm{C}$ labeled GPR. (a) Different ${ }^{13} \mathrm{C}$ reporters introduced via sparse and selective isotope labeling are highlighted in the PR structural model. A separate sample has been prepared for each labelling schemes. The ${ }^{13} \mathrm{C}-{ }^{13} \mathrm{C}$ SD build-up has then been measured in each of these samples. (b) Carbon-carbon distances $r$ between $\mathrm{C} 20$ and protein sites extracted from (a) plotted against the observed ${ }^{13} \mathrm{C}-{ }^{13} \mathrm{C}$ SD time constant (TSD). The data set can be described by $r=\mathrm{A} * T_{S D}{ }^{\frac{1}{6}}$ as expected for ${ }^{13} \mathrm{C}-{ }^{13} \mathrm{C} \mathrm{SD}$. The gray curve corresponds to the best fit including all data, the black curve is the fitting result when ignoring the three outliers (see main text and $\mathrm{SI}$ for further details). The error bars present the standard deviations of TSD data fitting. Distance error bars were derived from structural variations between different protomers in the crystal structure (PDB 4JQ6). The data points are plotted in the same colors as the reporters highlighted in (a). 


\section{References}

1. Hu, F.; Luo, W.; Hong, M., Mechanisms of Proton Conduction and Gating in Influenza M2 Proton Channels from Solid-State NMR. Science 2010, 330 (6003), 505-508.

2. Sharma, M.; Yi, M.; Dong, H.; Qin, H.; Peterson, E.; Busath, D. D.; Zhou, H. X.; Cross, T. A., Insight into the mechanism of the influenza A proton channel from a structure in a lipid bilayer. Science 2010, 330 (6003), 509-12.

3. Lewandowski, J. R.; Halse, M. E.; Blackledge, M.; Emsley, L., Protein dynamics. Direct observation of hierarchical protein dynamics. Science 2015, 348 (6234), 578-81.

4. Marchanka, A.; Simon, B.; Althoff-Ospelt, G.; Carlomagno, T., RNA structure determination by solid-state NMR spectroscopy. Nature communications 2015, 6, 7024.

5. Andreas, L. B.; Jaudzems, K.; Stanek, J.; Lalli, D.; Bertarello, A.; Le Marchand, T.; CalaDe Paepe, D.; Kotelovica, S.; Akopjana, I.; Knott, B.; Wegner, S.; Engelke, F.; Lesage, A.; Emsley, L.; Tars, K.; Herrmann, T.; Pintacuda, G., Structure of fully protonated proteins by proton-detected magic-angle spinning NMR. Proc. Natl. Acad. Sci. U. S. A. 2016, 113 (33), 9187-92.

6. Medeiros-Silva, J.; Jekhmane, S.; Paioni, A. L.; Gawarecka, K.; Baldus, M.; Swiezewska, E.; Breukink, E.; Weingarth, M., High-resolution NMR studies of antibiotics in cellular membranes. Nat. Commun. 2018, 9 (1), 3963.

7. Quinn, C. M.; Wang, M.; Fritz, M. P.; Runge, B.; Ahn, J.; Xu, C.; Perilla, J. R.; Gronenborn, A. M.; Polenova, T., Dynamic regulation of HIV-1 capsid interaction with the restriction factor TRIM5alpha identified by magic-angle spinning NMR and molecular dynamics simulations. Proc. Natl. Acad. Sci. U. S. A. 2018, 115 (45), 11519-11524.

8. Shi, C.; He, Y.; Hendriks, K.; de Groot, B. L.; Cai, X.; Tian, C.; Lange, A.; Sun, H., A single NaK channel conformation is not enough for non-selective ion conduction. Nat. Commun. 2018, 9 (1), 717.

9. Wiegand, T.; Cadalbert, R.; Lacabanne, D.; Timmins, J.; Terradot, L.; Bockmann, A.; Meier, B. H., The conformational changes coupling ATP hydrolysis and translocation in a bacterial DnaB helicase. Nat. Commun. 2019, 10 (1), 31.

10. Frederick, K. K.; Michaelis, V. K.; Corzilius, B.; Ong, T. C.; Jacavone, A. C.; Griffin, R. G.; Lindquist, S., Sensitivity-enhanced NMR reveals alterations in protein structure by cellular milieus. Cell 2015, 163 (3), 620-8.

11. Stoppler, D.; Song, C.; van Rossum, B. J.; Geiger, M. A.; Lang, C.; Mroginski, M. A.; Jagtap, A. P.; Sigurdsson, S. T.; Matysik, J.; Hughes, J.; Oschkinat, H., Dynamic Nuclear Polarization Provides New Insights into Chromophore Structure in Phytochrome Photoreceptors. Angewandte Chemie-International Edition 2016, 55 (52), 16017-16020.

12. Sergeyev, I. V.; Itin, B.; Rogawski, R.; Day, L. A.; McDermott, A. E., Efficient assignment and NMR analysis of an intact virus using sequential side-chain correlations and DNP sensitization. Proc Natl Acad Sci U S A 2017, 114 (20), 5171-5176.

13. Jaudzems, K.; Bertarello, A.; Chaudhari, S. R.; Pica, A.; Cala-De Paepe, D.; BarbetMassin, E.; Pell, A. J.; Akopjana, I.; Kotelovica, S.; Gajan, D.; Ouari, O.; Tars, K.; Pintacuda, G.; Lesage, A., Dynamic Nuclear Polarization-Enhanced Biomolecular NMR Spectroscopy at High Magnetic Field with Fast Magic-Angle Spinning. Angew. Chem. Int. Ed. Engl. 2018, 57 (25), 7458-7462.

14. Mao, J.; Do, N. N.; Scholz, F.; Reggie, L.; Mehler, M.; Lakatos, A.; Ong, Y. S.; Ullrich, S. J.; Brown, L. J.; Brown, R. C.; Becker-Baldus, J.; Wachtveitl, J.; Glaubitz, C., Structural basis of the green-blue color switching in proteorhodopsin as determined by NMR spectroscopy. J. Am. Chem. Soc. 2014, 136 (50), 17578-90.

15. Becker-Baldus, J.; Bamann, C.; Saxena, K.; Gustmann, H.; Brown, L. J.; Brown, R. C.; Reiter, C.; Bamberg, E.; Wachtveitl, J.; Schwalbe, H.; Glaubitz, C., Enlightening the photoactive site of channelrhodopsin-2 by DNP-enhanced solid-state NMR spectroscopy. Proc Natl Acad Sci U S A 2015, 112 (32), 9896-901.

16. Kaplan, M.; Cukkemane, A.; van Zundert, G. C.; Narasimhan, S.; Daniels, M.; Mance, D.; Waksman, G.; Bonvin, A. M.; Fronzes, R.; Folkers, G. E.; Baldus, M., Probing a cell- 
embedded megadalton protein complex by DNP-supported solid-state NMR. Nat. Methods 2015, 12 (7), 649-52.

17. Maciejko, J.; Mehler, M.; Kaur, J.; Lieblein, T.; Morgner, N.; Ouari, O.; Tordo, P.; BeckerBaldus, J.; Glaubitz, C., Visualizing Specific Cross-Protomer Interactions in the HomoOligomeric Membrane Protein Proteorhodopsin by Dynamic-Nuclear-PolarizationEnhanced Solid-State NMR. J. Am. Chem. Soc. 2015, 137 (28), 9032-43.

18. Kaplan, M.; Narasimhan, S.; de Heus, C.; Mance, D.; van Doorn, S.; Houben, K.; PopovCeleketic, D.; Damman, R.; Katrukha, E. A.; Jain, P.; Geerts, W. J. C.; Heck, A. J. R.; Folkers, G. E.; Kapitein, L. C.; Lemeer, S.; van Bergen En Henegouwen, P. M. P.; Baldus, M., EGFR Dynamics Change during Activation in Native Membranes as Revealed by NMR. Cell 2016, 167 (5), 1241-1251 e11.

19. Lehnert, E.; Mao, J.; Mehdipour, A. R.; Hummer, G.; Abele, R.; Glaubitz, C.; Tampe, R., Antigenic Peptide Recognition on the Human ABC Transporter TAP Resolved by DNPEnhanced Solid-State NMR Spectroscopy. J. Am. Chem. Soc. 2016, 138 (42), 1396713974.

20. Joedicke, L.; Mao, J.; Kuenze, G.; Reinhart, C.; Kalavacherla, T.; Jonker, H. R. A.; Richter, C.; Schwalbe, H.; Meiler, J.; Preu, J.; Michel, H.; Glaubitz, C., The molecular basis of subtype selectivity of human kinin G-protein-coupled receptors. Nat. Chem. Biol. 2018, 14 (3), 284-290.

21. Kaur, H.; Abreu, B.; Akhmetzyanov, D.; Lakatos-Karoly, A.; Soares, C. M.; Prisner, T.; Glaubitz, C., Unexplored Nucleotide Binding Modes for the ABC Exporter MsbA. J. Am. Chem. Soc. 2018, 140 (43), 14112-14125.

22. Ni, Q. Z.; Can, T. V.; Daviso, E.; Belenky, M.; Griffin, R. G.; Herzfeld, J., Primary Transfer Step in the Light-Driven Ion Pump Bacteriorhodopsin: An Irreversible U-Turn Revealed by Dynamic Nuclear Polarization-Enhanced Magic Angle Spinning NMR. J. Am. Chem. Soc. 2018, 140 (11), 4085-4091.

23. Nogly, P.; Weinert, T.; James, D.; Carbajo, S.; Ozerov, D.; Furrer, A.; Gashi, D.; Borin, V.; Skopintsev, P.; Jaeger, K.; Nass, K.; Bath, P.; Bosman, R.; Koglin, J.; Seaberg, M.; Lane, T.; Kekilli, D.; Brunle, S.; Tanaka, T.; Wu, W.; Milne, C.; White, T.; Barty, A.; Weierstall, U.; Panneels, V.; Nango, E.; Iwata, S.; Hunter, M.; Schapiro, I.; Schertler, G.; Neutze, R.; Standfuss, J., Retinal isomerization in bacteriorhodopsin captured by a femtosecond x-ray laser. Science 2018, 361 (6398).

24. Nass Kovacs, G.; Colletier, J. P.; Grunbein, M. L.; Yang, Y.; Stensitzki, T.; Batyuk, A.; Carbajo, S.; Doak, R. B.; Ehrenberg, D.; Foucar, L.; Gasper, R.; Gorel, A.; Hilpert, M.; Kloos, M.; Koglin, J. E.; Reinstein, J.; Roome, C. M.; Schlesinger, R.; Seaberg, M.; Shoeman, R. L.; Stricker, M.; Boutet, S.; Haacke, S.; Heberle, J.; Heyne, K.; Domratcheva, T.; Barends, T. R. M.; Schlichting, I., Three-dimensional view of ultrafast dynamics in photoexcited bacteriorhodopsin. Nat. Commun. 2019, 10 (1), 3177.

25. Liang, Y. L.; Khoshouei, M.; Radjainia, M.; Zhang, Y.; Glukhova, A.; Tarrasch, J.; Thal, D. M.; Furness, S. G. B.; Christopoulos, G.; Coudrat, T.; Danev, R.; Baumeister, W.; Miller, L. J.; Christopoulos, A.; Kobilka, B. K.; Wootten, D.; Skiniotis, G.; Sexton, P. M., Phase-plate cryo-EM structure of a class B GPCR-G-protein complex. Nature 2017, 546 (7656), 118123.

26. Lu, P.; Bai, X. C.; Ma, D.; Xie, T.; Yan, C.; Sun, L.; Yang, G.; Zhao, Y.; Zhou, R.; Scheres, S. H. W.; Shi, Y., Three-dimensional structure of human gamma-secretase. Nature 2014, 512 (7513), 166-170.

27. Keeler, J., Understanding NMR Spectroscopy, 2nd Ed. Wiley: 2010.

28. Daube, D.; Aladin, V.; Heiliger, J.; Wittmann, J. J.; Barthelmes, D.; Bengs, C.; Schwalbe, H.; Corzilius, B., Heteronuclear Cross-Relaxation under Solid-State Dynamic Nuclear Polarization. J. Am. Chem. Soc. 2016, 138 (51), 16572-16575.

29. Hoffmann, M. M.; Bothe, S.; Gutmann, T.; Hartrnann, F. F.; Reggelin, M.; Buntkowsky, G., Directly vs Indirectly Enhanced C-13 in Dynamic Nuclear Polarization Magic Angle Spinning NMR Experiments of Nonionic Surfactant Systems. Journal of Physical Chemistry C 2017, 121 (4), 2418-2427.

30. Rosenzweig, R.; Kay, L. E., Bringing dynamic molecular machines into focus by methylTROSY NMR. Annu. Rev. Biochem. 2014, 83, 291-315. 
31. Wiesner, S.; Sprangers, R., Methyl groups as NMR probes for biomolecular interactions. Curr. Opin. Struct. Biol. 2015, 35, 60-7.

32. Agarwal, V.; Penzel, S.; Szekely, K.; Cadalbert, R.; Testori, E.; Oss, A.; Past, J.; Samoson, A.; Ernst, M.; Bockmann, A.; Meier, B. H., De novo 3D structure determination from submilligram protein samples by solid-state $100 \mathrm{kHz}$ MAS NMR spectroscopy. Angew. Chem. Int. Ed. Engl. 2014, 53 (45), 12253-6.

33. Agarwal, V.; Xue, Y.; Reif, B.; Skrynnikov, N. R., Protein side-chain dynamics as observed by solution- and solid-state NMR spectroscopy: a similarity revealed. J. Am. Chem. Soc. 2008, 130 (49), 16611-21.

34. Linser, R.; Bardiaux, B.; Higman, V.; Fink, U.; Reif, B., Structure calculation from unambiguous long-range amide and methyl $1 \mathrm{H}-1 \mathrm{H}$ distance restraints for a microcrystalline protein with MAS solid-state NMR spectroscopy. J. Am. Chem. Soc. 2011, 133 (15), 590512.

35. Xue, Y.; Pavlova, M. S.; Ryabov, Y. E.; Reif, B.; Skrynnikov, N. R., Methyl rotation barriers in proteins from $2 \mathrm{H}$ relaxation data. Implications for protein structure. J. Am. Chem. Soc. 2007, 129 (21), 6827-38.

36. Zech, S. G.; Olejniczak, E.; Hajduk, P.; Mack, J.; McDermott, A. E., Characterization of protein-ligand interactions by high-resolution solid-state NMR spectroscopy. J. Am. Chem. Soc. 2004, 126 (43), 13948-53.

37. del Amo, J. M.; Agarwal, V.; Sarkar, R.; Porter, J.; Asami, S.; Rubbelke, M.; Fink, U.; Xue, Y.; Lange, O. F.; Reif, B., Site-specific analysis of heteronuclear Overhauser effects in microcrystalline proteins. J. Biomol. NMR 2014, 59 (4), 241-9.

38. Vugmeyster, L.; Ostrovsky, D.; Ford, J. J.; Burton, S. D.; Lipton, A. S.; Hoatson, G. L.; Vold, R. L., Probing the dynamics of a protein hydrophobic core by deuteron solid-state nuclear magnetic resonance spectroscopy. J. Am. Chem. Soc. 2009, 131 (38), 13651-8.

39. White, J. L.; Haw, J. F., Nuclear Overhauser Effect in Solids. J. Am. Chem. Soc. 1990, 112 (15), 5896-5898.

40. Katoh, E.; Takegoshi, K.; Terao, T., 13C nuclear overhauser polarization-magic-angle spinning nuclear magnetic resonance spectroscopy in uniformly 13C-labeled solid proteins. J. Am. Chem. Soc. 2004, 126 (11), 3653-7.

41. Ashbrook, S. E.; Dowell, N. G.; Prokes, I.; Wimperis, S., Nuclear Overhauser effect (NOE) enhancement of 11B NMR spectra of borane adducts in the solid state. J. Am. Chem. Soc. 2006, 128 (21), 6782-3.

42. Giraud, N.; Sein, J.; Pintacuda, G.; Bockmann, A.; Lesage, A.; Blackledge, M.; Emsley, L., Observation of heteronuclear overhauser effects confirms the $15 \mathrm{~N}-1 \mathrm{H}$ dipolar relaxation mechanism in a crystalline protein. J. Am. Chem. Soc. 2006, 128 (38), 12398-9.

43. Hong, M.; Schmidt-Rohr, K., Magic-angle-spinning NMR techniques for measuring longrange distances in biological macromolecules. Acc. Chem. Res. 2013, 46 (9), 2154-63.

44. Rossini, A. J.; Widdifield, C. M.; Zagdoun, A.; Lelli, M.; Schwarzwalder, M.; Coperet, C.; Lesage, A.; Emsley, L., Dynamic nuclear polarization enhanced NMR spectroscopy for pharmaceutical formulations. J. Am. Chem. Soc. 2014, 136 (6), 2324-34.

45. Bjorgvinsdottir, S.; Walder, B. J.; Pinon, A. C.; Emsley, L., Bulk Nuclear Hyperpolarization of Inorganic Solids by Relay from the Surface. J. Am. Chem. Soc. 2018, 140 (25), 79467951.

46. Wang, M.; Lu, M.; Fritz, M. P.; Quinn, C. M.; Byeon, I. L.; Byeon, C. H.; Struppe, J.; Maas, W.; Gronenborn, A. M.; Polenova, T., Fast Magic-Angle Spinning (19) F NMR Spectroscopy of HIV-1 Capsid Protein Assemblies. Angew. Chem. Int. Ed. Engl. 2018, 57 (50), 16375-16379.

47. Beja, O.; Aravind, L.; Koonin, E. V.; Suzuki, M. T.; Hadd, A.; Nguyen, L. P.; Jovanovich, S. B.; Gates, C. M.; Feldman, R. A.; Spudich, J. L.; Spudich, E. N.; DeLong, E. F., Bacterial rhodopsin: evidence for a new type of phototrophy in the sea. Science 2000, 289 (5486), 1902-6.

48. Fuhrman, J. A.; Schwalbach, M. S.; Stingl, U., Proteorhodopsins: an array of physiological roles? Nat. Rev. Microbiol. 2008, 6 (6), 488-94.

49. Bamann, C.; Bamberg, E.; Wachtveitl, J.; Glaubitz, C., Proteorhodopsin. Biochim. Biophys. Acta 2014, 1837 (5), 614-25. 
50. Friedrich, T.; Geibel, S.; Kalmbach, R.; Chizhov, I.; Ataka, K.; Heberle, J.; Engelhard, M.; Bamberg, E., Proteorhodopsin is a light-driven proton pump with variable vectoriality. $J$. Mol. Biol. 2002, 321 (5), 821-38.

51. Mehler, M.; Eckert, C. E.; Leeder, A. J.; Kaur, J.; Fischer, T.; Kubatova, N.; Brown, L. J.; Brown, R. C. D.; Becker-Baldus, J.; Wachtveitl, J.; Glaubitz, C., Chromophore Distortions in Photointermediates of Proteorhodopsin Visualized by Dynamic Nuclear PolarizationEnhanced Solid-State NMR. J. Am. Chem. Soc. 2017, 139 (45), 16143-16153.

52. Maciejko, J.; Kaur, J.; Becker-Baldus, J.; Glaubitz, C., Photocycle-dependent conformational changes in the proteorhodopsin cross-protomer Asp-His-Trp triad revealed by DNP-enhanced MAS-NMR. Proc. Natl. Acad. Sci. U. S. A. 2019, 116 (17), 8342-8349.

53. Yang, J.; Aslimovska, L.; Glaubitz, C., Molecular dynamics of proteorhodopsin in lipid bilayers by solid-state NMR. J. Am. Chem. Soc. 2011, 133 (13), 4874-81.

54. Shi, L.; Lake, E. M.; Ahmed, M. A.; Brown, L. S.; Ladizhansky, V., Solid-state NMR study of proteorhodopsin in the lipid environment: secondary structure and dynamics. Biochim. Biophys. Acta 2009, 1788 (12), 2563-74.

55. Hempelmann, F.; Holper, S.; Verhoefen, M. K.; Woerner, A. C.; Kohler, T.; Fiedler, S. A.; Pfleger, N.; Wachtveitl, J.; Glaubitz, C., His75-Asp97 cluster in green proteorhodopsin. J. Am. Chem. Soc. 2011, 133 (12), 4645-54.

56. Ran, T.; Ozorowski, G.; Gao, Y.; Sineshchekov, O. A.; Wang, W.; Spudich, J. L.; Luecke, $\mathrm{H}$., Cross-protomer interaction with the photoactive site in oligomeric proteorhodopsin complexes. Acta Crystallogr. D Biol. Crystallogr. 2013, 69 (Pt 10), 1965-80.

57. Lalli, D.; Idso, M. N.; Andreas, L. B.; Hussain, S.; Baxter, N.; Han, S.; Chmelka, B. F.; Pintacuda, G., Proton-Based Structural Analysis of a Heptahelical Transmembrane Protein in Lipid Bilayers. J. Am. Chem. Soc. 2017, 139 (37), 13006-13012.

58. Hussain, S.; Franck, J. M.; Han, S., Transmembrane protein activation refined by sitespecific hydration dynamics. Angewandte Chemie (International ed. in English) 2013, 52 (7).

59. Aladin, V.; Corzilius, B., Methyl dynamics in amino acids modulate heteronuclear cross relaxation in the solid state under MAS DNP. Solid State Nucl. Magn. Reson. 2019, 99, $27-$ 35.

60. Sauvee, C.; Rosay, M.; Casano, G.; Aussenac, F.; Weber, R. T.; Ouari, O.; Tordo, P., Highly efficient, water-soluble polarizing agents for dynamic nuclear polarization at high frequency. Angew. Chem. Int. Ed. Engl. 2013, 52 (41), 10858-61.

61. Aladin, V.; Vogel, M.; Binder, R.; Burghardt, I.; Suess, B.; Corzilius, B., Complex Formation of the Tetracycline-Binding Aptamer Investigated by Specific Cross-Relaxation under DNP. Angewandte Chemie-International Edition 2019, 58 (15), 4863-4868.

62. Hu, K. N.; Yu, H. H.; Swager, T. M.; Griffin, R. G., Dynamic nuclear polarization with biradicals. J. Am. Chem. Soc. 2004, 126 (35), 10844-10845.

63. Mellink, W. A.; Kaptein, R., Determination of the methyl-group rotation energy barrier in some substituted tricyclo $3.1 .0 .02,6$ hexanes by $\mathrm{C}-13$ spin-lattice relaxation. Org Magn Resonance 1980, 13 (4), 279-281.

64. Struts, A. V.; Salgado, G. F.; Martinez-Mayorga, K.; Brown, M. F., Retinal dynamics underlie its switch from inverse agonist to agonist during rhodopsin activation. Nat. Struct. Mol. Biol. 2011, 18 (3), 392-4.

65. Bajaj, V. S.; Mak-Jurkauskas, M. L.; Belenky, M.; Herzfeld, J.; Griffin, R. G., Functional and shunt states of bacteriorhodopsin resolved by $250 \mathrm{GHz}$ dynamic nuclear polarizationenhanced solid-state NMR. Proc Natl Acad Sci U S A 2009, 106 (23), 9244-9249.

66. Yomoda, H.; Makino, Y.; Tomonaga, Y.; Hidaka, T.; Kawamura, I.; Okitsu, T.; Wada, A.; Sudo, Y.; Naito, A., Color-discriminating retinal configurations of sensory rhodopsin I by photo-irradiation solid-state NMR spectroscopy. Angew. Chem. Int. Ed. Engl. 2014, 53 (27), 6960-4.

67. Fu, R.; Li, J.; Cui, J.; Peng, X., Revisiting spin-lattice relaxation time measurements for dilute spins in high-resolution solid-state NMR spectroscopy. J. Magn. Reson. 2016, 268, 107-113. 
68. Viennet, T.; Viegas, A.; Kuepper, A.; Arens, S.; Gelev, V.; Petrov, O.; Grossmann, T. N.; Heise, H.; Etzkorn, M., Selective Protein Hyperpolarization in Cell Lysates Using Targeted Dynamic Nuclear Polarization. Angew. Chem. Int. Ed. Engl. 2016, 55 (36), 10746-50.

69. Rogawski, R.; Sergeyev, I. V.; Li, Y. J.; Ottaviani, M. F.; Cornish, V.; McDermott, A. E., Dynamic Nuclear Polarization Signal Enhancement with High-Affinity Biradical Tags. J. Phys. Chem. B 2017, 121 (6), 1169-1175.

70. Marin-Montesinos, I.; Goyard, D.; Gillon, E.; Renaudet, O.; Imberty, A.; Hediger, S.; De Paepe, G., Selective high-resolution DNP-enhanced NMR of biomolecular binding sites. Chem. Sci. 2019, 10 (11), 3366-3374.

71. Elena, B.; Pintacuda, G.; Mifsud, N.; Emsley, L., Molecular structure determination in powders by NMR crystallography from proton spin diffusion. J. Am. Chem. Soc. 2006, 128 (29), 9555-60.

72. Lu, X.; Guo, C.; Hou, G.; Polenova, T., Combined zero-quantum and spin-diffusion mixing for efficient homonuclear correlation spectroscopy under fast MAS: broadband recoupling and detection of long-range correlations. J. Biomol. NMR 2015, 61 (1), 7-20.

73. Ladizhansky, V.; Griffin, R. G., Band-selective carbonyl to aliphatic side chain 13C-13C distance measurements in U-13C,15N-labeled solid peptides by magic angle spinning NMR. J. Am. Chem. Soc. 2004, 126 (3), 948-58.

74. Morcombe, C. R.; Gaponenko, V.; Byrd, R. A.; Zilm, K. W., Diluting abundant spins by isotope edited radio frequency field assisted diffusion. J. Am. Chem. Soc. 2004, 126 (23), 7196-7.

75. van der Wel, P. C.; Eddy, M. T.; Ramachandran, R.; Griffin, R. G., Targeted 13C-13C distance measurements in a microcrystalline protein via J-decoupled rotational resonance width measurements. Chemphyschem 2009, 10 (9-10), 1656-63.

76. Fry, E. A.; Sengupta, S.; Phan, V. C.; Kuang, S.; Zilm, K. W., CSA-enabled spin diffusion leads to MAS rate-dependent T1's at high field. J. Am. Chem. Soc. 2011, 133 (5), 1156-8.

77. Gartner, W.; Towner, P.; Hopf, H.; Oesterhelt, D., Removal of Methyl-Groups from Retinal Controls the Activity of Bacteriorhodopsin. Biochemistry 1983, 22 (11), 2637-2644.

78. Logunov, S. L.; el-Sayed, M. A.; Lanyi, J. K., Replacement effects of neutral amino acid residues of different molecular volumes in the retinal binding cavity of bacteriorhodopsin on the dynamics of its primary process. Biophys. J. 1996, 70 (6), 2875-81.

79. Malmerberg, E.; Omran, Z.; Hub, J. S.; Li, X.; Katona, G.; Westenhoff, S.; Johansson, L. C.; Andersson, M.; Cammarata, M.; Wulff, M.; van der Spoel, D.; Davidsson, J.; Specht, A.; Neutze, R., Time-resolved WAXS reveals accelerated conformational changes in iodoretinal-substituted proteorhodopsin. Biophys. J. 2011, 101 (6), 1345-53.

80. Feng, J.; Mertz, B., Proteorhodopsin Activation Is Modulated by Dynamic Changes in Internal Hydration. Biochemistry 2015, 54 (48), 7132-41.

81. Andersson, M.; Malmerberg, E.; Westenhoff, S.; Katona, G.; Cammarata, M.; Wohri, A. B.; Johansson, L. C.; Ewald, F.; Eklund, M.; Wulff, M.; Davidsson, J.; Neutze, R., Structural dynamics of light-driven proton pumps. Structure 2009, 17 (9), 1265-75.

82. Nango, E.; Royant, A.; Kubo, M.; Nakane, T.; Wickstrand, C.; Kimura, T.; Tanaka, T.; Tono, K.; Song, C.; Tanaka, R.; Arima, T.; Yamashita, A.; Kobayashi, J.; Hosaka, T.; Mizohata, E.; Nogly, P.; Sugahara, M.; Nam, D.; Nomura, T.; Shimamura, T.; Im, D.; Fujiwara, T.; Yamanaka, Y.; Jeon, B.; Nishizawa, T.; Oda, K.; Fukuda, M.; Andersson, R.; Bath, P.; Dods, R.; Davidsson, J.; Matsuoka, S.; Kawatake, S.; Murata, M.; Nureki, O.; Owada, S.; Kameshima, T.; Hatsui, T.; Joti, Y.; Schertler, G.; Yabashi, M.; Bondar, A. N.; Standfuss, J.; Neutze, R.; Iwata, S., A three-dimensional movie of structural changes in bacteriorhodopsin. Science 2016, 354 (6319), 1552-1557.

83. Ikeda, D.; Furutani, Y.; Kandori, H., FTIR study of the retinal Schiff base and internal water molecules of proteorhodopsin. Biochemistry 2007, 46 (18), 5365-73.

84. Neumann-Verhoefen, M. K.; Neumann, K.; Bamann, C.; Radu, I.; Heberle, J.; Bamberg, E.; Wachtveitl, J., Ultrafast infrared spectroscopy on channelrhodopsin-2 reveals efficient energy transfer from the retinal chromophore to the protein. J. Am. Chem. Soc. 2013, 135 (18), 6968-76.

85. Leeder, A. J.; Brown, L. J.; Becker-Baldus, J.; Mehler, M.; Glaubitz, C.; Brown, R. C. D., Synthesis of isotopically labeled all-trans retinals for DNP-enhanced solid-state NMR 
studies of retinylidene proteins. J. Labelled Compd. Radiopharmaceut. 2018, 61 (13), $922-$ 933.

86. AzimiHashemi, N.; Erbguth, K.; Vogt, A.; Riemensperger, T.; Rauch, E.; Woodmansee, D.; Nagpal, J.; Brauner, M.; Sheves, M.; Fiala, A.; Kattner, L.; Trauner, D.; Hegemann, P.; Gottschalk, A.; Liewald, J. F., Synthetic retinal analogues modify the spectral and kinetic characteristics of microbial rhodopsin optogenetic tools. Nat. Commun. 2014, 5.

87. Fung, B. M.; Khitrin, A. K.; Ermolaev, K., An improved broadband decoupling sequence for liquid crystals and solids. J. Magn. Reson. 2000, 142 (1), 97-101.

88. Mao, J.; Akhmetzyanov, D.; Ouari, O.; Denysenkov, V.; Corzilius, B.; Plackmeyer, J.; Tordo, P.; Prisner, T. F.; Glaubitz, C., Host-guest complexes as water-soluble highperformance DNP polarizing agents. J. Am. Chem. Soc. 2013, 135 (51), 19275-81.

89. Hohwy, M.; Jakobsen, H. J.; Eden, M.; Levitt, M. H.; Nielsen, N. C., Broadband dipolar recoupling in the nuclear magnetic resonance of rotating solids: $\mathrm{A}$ compensated $\mathrm{C} 7$ pulse sequence. J. Chem. Phys. 1998, 108 (7), 2686-2694.

90. Frisch, M. J.; Trucks, G. W.; Schlegel, H. B.; Scuseria, G. E.; Robb, M. A.; Cheeseman, J. R.; Scalmani, G.; Barone, V.; Mennucci, B.; Petersson, G. A.; Nakatsuji, H.; Caricato, M.; Li, X.; Hratchian, H. P.; Izmaylov, A. F.; Bloino, J.; Zheng, G.; Sonnenberg, J. L.; Hada, M.; Ehara, M.; Toyota, K.; Fukuda, R.; Hasegawa, J.; Ishida, M.; Nakajima, T.; Honda, Y.; Kitao, O.; Nakai, H.; Vreven, T.; Montgomery, J. A.; Peralta, J. E.; Ogliaro, F.; Bearpark, M.; Heyd, J. J.; Brothers, E.; Kudin, K. N.; Staroverov, V. N.; Kobayashi, R.; Normand, J.; Raghavachari, K.; Rendell, A.; Burant, J. C.; Iyengar, S. S.; Tomasi, J.; Cossi, M.; Rega, N.; Millam, J. M.; Klene, M.; Knox, J. E.; Cross, J. B.; Bakken, V.; Adamo, C.; Jaramillo, J.; Gomperts, R.; Stratmann, R. E.; Yazyev, O.; Austin, A. J.; Cammi, R.; Pomelli, C.; Ochterski, J. W.; Martin, R. L.; Morokuma, K.; Zakrzewski, V. G.; Voth, G. A.; Salvador, P.; Dannenberg, J. J.; Dapprich, S.; Daniels, A. D.; Farkas, Ö.; Foresman, J. B.; Ortiz, J. V.; Cioslowski, J.; Fox, D. J., Gaussian 09, Revision C.01. Gaussian Inc Wallingford CT 2010.

91. Bayley, H.; Jayasinghe, L., Functional engineered channels and pores - (Review). Mol. Membr. Biol. 2004, 21 (4), 209-220.

92. Ji, C. G.; Mei, Y.; Zhang, J. Z. H., Developing polarized protein-specific charges for protein dynamics: MD free energy calculation of $\mathrm{pK}(\mathrm{a})$ shifts for $A s p(26) / A s p(20)$ in thioredoxin. Biophys. J. 2008, 95 (3), 1080-1088.

93. Rocchia, W.; Alexov, E.; Honig, B., Extending the applicability of the nonlinear PoissonBoltzmann equation: Multiple dielectric constants and multivalent ions. J. Phys. Chem. B 2001, 105 (28), 6507-6514.

94. Wang, X.; He, X.; Zhang, J. Z., Predicting mutation-induced Stark shifts in the active site of a protein with a polarized force field. J. Phys. Chem. A 2013, 117 (29), 6015-23.

95. Bayly, C. I.; Cieplak, P.; Cornell, W.; Kollman, P. A., A well-behaved electrostatic potential based method using charge restraints for deriving atomic charges: the RESP model. $J$. Phys. Chem. 1993, 97 (40), 10269-10280. 


\section{Table of Content Figure}
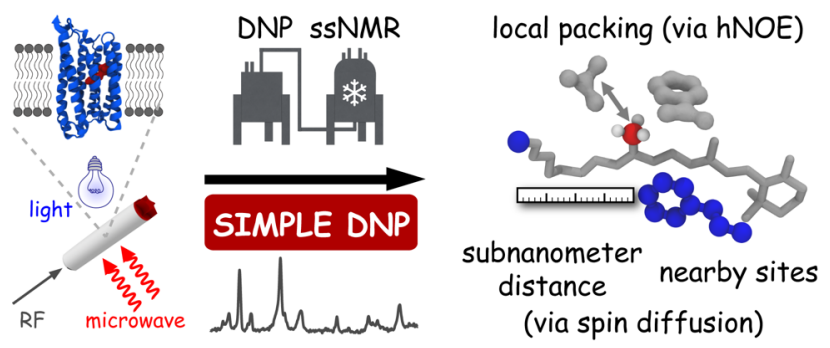